\title{
Capítulo
} 1

\section{Produção Tecnológica na IE: prospecção e propriedade intelectual em Informática na Educação}

\author{
Maria Augusta Silveira Netto Nunes
}

\begin{abstract}
This short course provides the knowhow for the Brazilian researchers and entrepreneurs on Computers in Education. The course discusses some issues related to intellectual property aroused from academic production and technological research from undergraduate and graduate (fostered by the Brazilian public money from scholarships of Scientific and Technological Initiation, Master, Doctorate and Postdoctorate). Whereas one of the Computer Science's big challenges appointed by SBC for the decade (2006-2016) is the integration with the industry, this short course aims to discuss the gap between science (academic production) and technological innovation (technological production). The short course covers the transition of the-state-of-the-art for the-state-of-technology, providing the knowhow for the professional (researcher/ businessman) to identify if their technology is an innovative product and if it could be developed by industry. Another topic covered by the short course is about national and international law related to intellectual property in relation to the profile of IE.
\end{abstract}

\section{Resumo}

Este capítulo traz subsídios ao público de Informática na Educação do país no que tange questões relacionadas à propriedade intelectual oriundas de produções acadêmicas/tecnológicas - frutos de pesquisas de graduação e de pós-graduação fomentadas, na maioria vezes, com dinheiro público brasileiro (via bolsas de Iniciação Científica, Iniciação Tecnológica, Mestrado, Doutorado e Pós-doutorado). Considerando que um dos Grandes Desafios científicos da Computação apontados pela SBC para a década (2006-2016) é a integração com a indústria, esse capitulo se propõe a discutir a lacuna existente entre a ciência (produção acadêmica) e a inovação tecnológica (produção tecnológica). O capítulo aborda a transição do estado da arte para o estado da técnica, possibilitando ao profissional (acadêmico/empresarial) identificar se o seu protótipo em desenvolvimento é um produto inovador elou se tem 
mercado (nacional elou internacional). Outro ponto abordado no capítulo é relativo às normatizações (nacional e internacional) de questões relacionadas à propriedade intelectual desse produto em relação ao perfil da IE.

\subsection{Introdução}

O empreendedorismo em mercados emergentes fruto de uma produção tecnológica nacional herdada ou transferida de uma produção acadêmica é um campo emergente e promissor que atualmente recebe incentivo e fomento governamental. Devido ao fato de ser um campo em expansão no Brasil, a comunidade acadêmica/empresarial muitas vezes não se encontra preparada e, a comunidade de Informática na Educação (IE) não é exceção. Nesses termos a comunidade de IE se apresenta com pouca informação e formação, principalmente, relacionada a fase intermediária entre a produção científica e a produção tecnológica e inovadora. Dessa forma, o papel do capítulo é de formação: pretende-se fornecer a operacionalização básica aos acadêmicos/profissionais de como prospectar a tecnologia, principalmente, em bases de patentes (produtos já existentes), e assim, possibilitar ao produtor de tecnologia a busca de lacunas para que seus novos produtos efetivamente tenham potencial para concorrer no mercado nacional e internacional.

Os produtos prospectados e criados na academia são o portfólio institucional da mesma, assim como a soma desses portfólios institucionais representa, em grande parte, o portfólio da produção tecnológica do Brasil, disponível nos indicadores nacionais/internacionais. A transferência de uma tecnologia é um passo posterior à operacionalização da criação de patentes de produtos baseados em tecnologias promissoras. Outro fator relevante, anterior à transferência de tecnologia, é a apropriação dessa tecnologia por quem é de direito, ou seja, os acadêmicos \& instituição pública onde o produto foi concebido, completando a holística do círculo virtuoso (recurso que fomenta a produção acadêmica retorna à instituição de origem por meio de royalties). Para a apropriação da tecnologia, deve-se conhecer a legislação brasileira e internacional sobre propriedade intelectual relacionada ao produto. Nesse sentido, este capítulo visa prover o conhecimento necessário para possibilitar a aproximação dos criadores da tecnologia (academia) aos responsáveis por transformarem a tecnologia em inovação nos/dos processos produtivos (indústria/empresariado) operacionalizando os mercados emergentes no país e no mundo.

Esse capítulo destina-se a acadêmicos (graduação e de pós-graduação), profissionais, professores e empresários interessados em compreender sobre Produção Tecnológica e Propriedade Intelectual no ramo de Informática e de Informática na Educação.

O texto está organizado como segue: na seção 2, disserta-se sobre a produção acadêmica \& a produção tecnológica; seguindo-se, na seção 3, pela apresentação das ferramentas de busca e operacionalização das prospecções; apresentando-se, na seção 4, as formas de proteção dos ativos em Informática na Educação, vinculando a área de software à Propriedade Intelectual e Industrial, bem como outros ativos passíveis de proteção em Informática na Educação; finalizando-se, na seção 5, pela conclusão, seguindo-se das referências bibliográficas. 


\subsection{Produção Acadêmica \& Produção tecnológica}

Segundo discutido em Nunes et al. (2013), observa-se que a Propriedade Intelectual não se constitui mais em algo tão distante do pesquisador, e a sua relevância na carreira do mesmo já é reconhecida por órgãos governamentais, como, por exemplo, o Conselho Nacional de Desenvolvimento Científico e Tecnológico (CNPq). Verifica-se esse fato ao visualizar os menus "Patentes e Registros" e "Inovação", disponíveis atualmente na Plataforma LATTES. O próprio MCTI (Ministério da Ciência, Tecnologia e Inovação) ratifica a importância do tema, disponibilizando o formulário eletrônico FORMICT (Formulário para Informações sobre a Política de Propriedade Intelectual das Instituições Científicas e Tecnológicas do Brasil), desde o ano de 2012, afim de que as instituições científicas e tecnológicas (ICT) encaminhem as informações relativas ao exercício do ano anterior, em relação às suas políticas de propriedade intelectual, criações desenvolvidas, proteções requeridas e concedidas e contratos de licenciamento ou de transferência de tecnologia firmados, atendendo ao disposto no Art. 17 da Lei de Inovação (Lei 10.973/2004). Adicionalmente, no âmbito das Universidades brasileiras, observa-se o forte movimento para a implantação dos NIT (Núcleos de Inovação Tecnológica), também em atendimento ao Art. 16 da Lei de Inovação - LI (2004).

Entretanto, nos últimos anos os cientistas brasileiros têm tido uma preocupação demasiada quanto à produção acadêmica, leia-se publicação de artigos. Isso tem acontecido devido à pressão dos órgãos que regulam e credenciam a ciência e tecnologia no Brasil. Como afirma De Negri e Cavalcante (2013), existe um crescente interesse público/governamental para que o conhecimento produzido em universidades e instituições de pesquisa seja transferido aos meios produtivos, aspirando acelerar o processo de desenvolvimento econômico do país. Portanto, tem-se notado que a teia da cadeia que abrange a produção acadêmico-científica brasileira não tem garantido que o conhecimento seja transferido tecnologicamente aos processos produtivos brasileiros, fomentando uma intensa geração de saberes que acabam sendo negligenciados no país, gerando, muitas vezes, royalties ao exterior. Um dos fatores que corrobora para esse processo é a falta de uma política de integração e troca de conhecimento entre universidade e empresa. Conforme discutido por Cruz (2000), a atenção quase exclusiva à academia, coloca às margens o setor empresarial, capaz de transformar conhecimento em riqueza. Porém, Scholze e Chamas (2000) destacam que a legislação de Propriedade Intelectual brasileira permite criar uma relação mais próxima entre as instituições de pesquisa, onde tradicionalmente a invenção é criada, e a indústria/empresa capaz de colocar as invenções no mercado. No entanto a inexistência da cultura de apropriação nacional oficial dos frutos que a produção científica brasileira contribui para que a relação universidade e indústria/empresa esteja distante. No Brasil, contudo, a participação relativamente reduzida dos investimentos empresariais no total dos investimentos em pesquisa e desenvolvimento $(\mathrm{P} \& \mathrm{D})$ e a evolução mais acelerada do número de publicações vis-à-vis o número de patentes consolidaram a percepção de que as políticas brasileiras de CT\&I ainda privilegiariam a produção científica e, de que, efetivamente, existe um reduzido nível de articulação entre as universidades, centros de pesquisa e o setor produtivo, segundo De Negri e Cavalcante (2013).

Assim, as últimas décadas têm sido marcadas pelo distanciamento entre os indicadores nacionais/internacionais de produção científica e os de produção tecnológica. A partir de 2006, os estudos brasileiros publicados em periódicos científicos internacionais indexados ao Institute for Scientific Information 
superaram a proporção de 250 artigos por milhão de habitantes, convergindo para a média mundial e levando a participação do país na produção científica mundial à ultrapassar 2,5\% no final de 2010. Entretanto, a participação do país nas concessões de patentes depositadas no United States Patents and Trademark Office (USPTO) - que, a despeito de suas limitações, representa um proxy da produção tecnológica, é da ordem de $0,1 \%$ do total mundial (SEI, 2012). Verifica-se, nesse contexto, que os Estados Unidos possui mais de $50 \%$ das patentes concedidas no montante mundial. Enquanto o Brasil possui apenas $0,1 \%$ da representatividade mundial na produção tecnológica (em 2002 e 2007). Quando analisada a produção científica, os Estados Unidos representa cerca de $26 \%$ mundiais em artigos de periódicos do Thomson Reuters, SCI e SSCI em 2009, conforme SEI (2012), contra apenas 1,6\% da produção científica brasileira em 2009 (na área tecnológica).

Enquanto o Brasil não se apropria do conhecimento científico aqui produzido, o mundo então se apropria desse conhecimento brasileiro publicado nos veículos internacionais, transformando-os em processos produtivos proprietários estrangeiros. Esses processos produtivos proprietários, muitas vezes, acabam retornando ao Brasil como propriedade estrangeira, gerando royalties ao exterior.

Em países como os Estados Unidos, detentores de um número enorme de patentes mundiais, existe uma preocupação intrínseca e crescente que a produção científica nacional americana seja mantida proprietária e efetivamente usada no desenvolvimento de novas tecnologias. Isso é percebido a partir da análise das patentes depositadas no USPTO, conforme UNESCO e SEI (2010, 2012). Observa-se que é crescente o número de citações de artigos científicos nestas patentes, segundo SEI (2012). Ainda, de acordo com o SEI (2012), as publicações científicas refletem as contribuições em nível de conhecimento, enquanto patentes indicam invenções úteis. Entretanto, as citações de patentes em artigos \& as citações de artigos em patentes indicam o link entre pesquisa científica e aplicação prática nos processos produtivos. Geralmente, é grande a probabilidade de que as citações se refiram às publicações de pesquisadores da mesma nacionalidade do titular da patente, de acordo com a SEI (2012). Esse cenário infelizmente não se reproduz no Brasil. O que é preocupante nesse cenário é a captura, pelas equipes estrangeiras, da não apropriada/registrada propriedade intelectual nacional brasileira, que acabam levando o conhecimento de forma indireta aos países de origem estrangeira e possivelmente transformando-o em produto, que a posteriori retorna ao Brasil como produto exportado gerando receita e royalties ao exterior.

\subsection{Busca e Prospeç̧ão}

Como sinalizado anteriormente, a produção acadêmica, geralmente, é operacionalizada, na maioria das vezes, por meio de artigos publicados em periódicos indexados, enquanto a produção tecnológica é operacionalizada pela criação de produtos, sua apropriação e posterior transferência desses para os processos produtivos. Entretanto, existem lacunas que dificultam a holística do processo produção acadêmica \& produção tecnológica \& transferência de tecnologia para os processos produtivos. Uma dessas lacunas pode ser percebida como a falta de informação do pesquisador/acadêmico em operacionalizar o conhecimento sobre o perfil mercadológico da tecnologia (protótipo ou produto) criada em laboratório originária de suas produções acadêmicas. Algumas questões que podem ser levantadas são as seguintes: (i) A tecnologia produzida no 
laboratório é uma inovação? É uma inovação de processo ou de produto? (ii) Essa tecnologia já existe comercialmente? Ou seja, a mesma já foi apropriada/patenteada? Foi ou está sendo comercializada? (iii) Se a tecnologia já foi patenteada, como encontrar lacunas nessa tecnologia? (iv) Se a tecnologia não foi patenteada, é necessário verificar se a mesma têm mercado e é passível de interesse dos processos produtivos... Nesse contexto, os métodos de busca e prospecção de tecnologia podem auxiliar o acadêmico a compreender como uma tecnologia específica se posiciona frente a outras tecnologias no mercado, segundo Russo et al. (2012).

Existem dois principais métodos de busca: (i) a busca de anterioridade e (ii) a prospecção tecnológica. No primeiro caso (i), o objetivo é avaliar se a tecnologia em desenvolvimento já foi anteriormente desenvolvida e apropriada ou se está em utilização pela sociedade. No segundo caso (ii), o objetivo é a melhor compreensão da tecnologia, identificando seu estágio de aplicação, sua maturidade, seus aspectos em relação às tecnologias concorrentes e suas lacunas existentes visando à criação de tecnologias competitivas. $\mathrm{Na}$ Prospecção, principalmente, pode-se identificar tecnologias competidoras e afins que podem ser incorporadas à tecnologia que está sendo proposta, bem como se pode identificar parceiros e competidores, segundo Russo et al. (2012).

Tanto a busca de anterioridade como a prospecção tecnológica pode utilizar para a catalogação de suas buscas: os documentos provenientes de domínio público de publicações científicas, bem como os documentos referentes às tecnologias já apropriadas e disponíveis nas bases de patentes. Entretanto, a prospecção tecnológica é mais ampla e profunda que a busca de anterioridade e utiliza essencialmente os registros de patentes em suas estratégias de busca. Segundo a WIPO (2013), 70\% das informações tecnológicas são encontradas somente em registros de patentes. Dessa forma, para viabilizar a concepção das prospecções pelos acadêmicos, primeiramente apresenta-se as bases de busca de registros de patentes mais reputadas atualmente, como segue.

\subsubsection{Bases de Busca de Registros de Patentes}

\subsubsection{EPO}

A European Patent Office (EPO) é uma organização intergovernamental criada em 7 de outubro de 1977 com base na Convenção Europeia de Patentes (EPC-European Patent Convention) assinado em Munique em 1973, EPO (2013). A EPO possui uma base de dados para busca de patentes intitulada de esp@cenet. No esp@cenet encontram-se aproximadamente 80 milhões de pedidos de patentes mundiais, desses, existem patentes depositadas e patentes concedidas, tanto europeias, como mundiais. O esp@cenet abrange depósitos e concessões de patentes a partir do ano de 1836. O banco de dados doesp@cenet é atualizado semanalmente e cobre todas as áreas de conhecimento. $\mathrm{O}$ acesso ao documento de registro de patente na integra é disponibilizado após 18 meses da data de depósito, devido ao tempo de sigilo (como acontece em todas as outras bases de busca). O documento é disponibilizado na integra, principalmente nos casos em que o mesmo foi depositado via EPO, caso contrário, o documento pode ser acessado de forma parcial de acordo com os contratos pré-existente entre os escritórios dos países depositantes/cossignatários, ver detalhes em EPO (2011). 
Visando facilitar as buscas, o esp@cenet possui uma interface que possibilita a consulta em diversos idiomas, incluindo, também, a tradução das patentes em alguns desses idiomas. Existem, ainda, facilidades de impressão e armazenamento das consultas/patentes (considerando os acordos citados anteriormente). As pesquisas realizadas via esp@cenet possibilitam o uso de operadores booleanos e caracteres de truncamento, tais como : (i) * para um número limitado de caracteres; (ii) ? para 0 ou um caractere e (iii) \# para um caractere, exatamente.

Para realizar uma busca no esp@cenet, o pesquisador deve digitar o endereço da EPO, www.epo.org, em seguida clicar em "search for patents", seguido pelo clique em "esp@cenet-worldwide patente search", como visto na Figura 1.1.

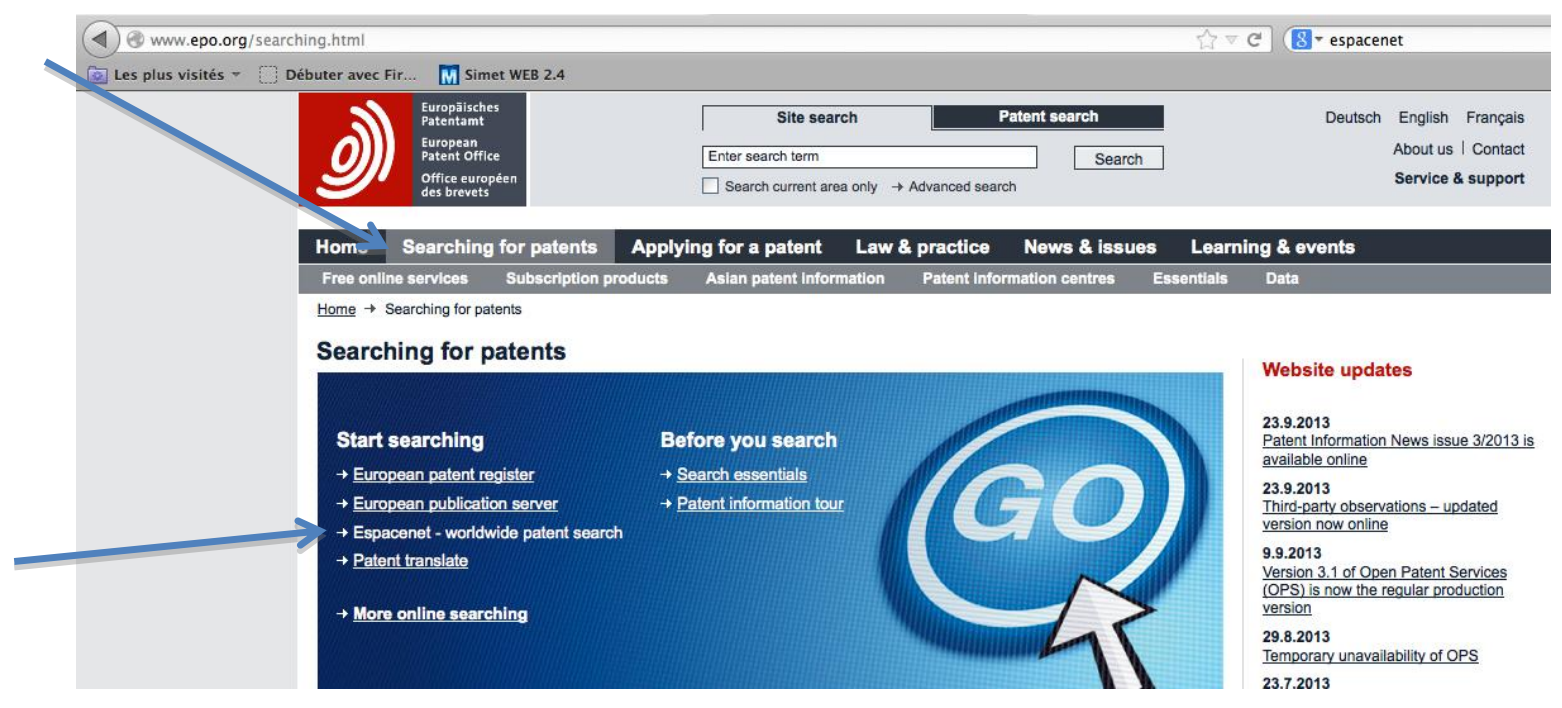

Figura 1.1. Como realizar a busca no esp@cenet

Após o acesso à busca avançada, como visto na Figura 1.2, o pesquisador pode inserir os termos para a busca. Normalmente, pesquisadores com menos experiência devem optar pelo uso de palavras-chaves/termos no título e abstract (resumo). Existem diversas outros campos que permitem uma maior filtragem às buscas, tais como 0 número de patentes, o código IPC/CIP ${ }^{1}$, conforme CIP (2006), dentre outros. Veja na Figura 1.2, os principais campos descritos acima, veja também que o usuário pode selecionar a coleção "esp@cenet” onde deseja que a busca seja realizada.

$\mathrm{Na}$ Figura 1.2, de forma ilustrativa, utilizou-se a palavra-chave/termo "Intelligent tutoring system". O resultado da busca na base esp@cenet, como visto na Figura 1.3, retornou 16 patentes referentes ao termo pesquisado, "Intelligent tutoring system", tanto no título das patentes quanto nos resumos (na Figura 1.3 aparecem somente duas patentes, porém se o usuário replicar a pesquisa e usar a barra de rolagem terá acesso ao conjunto de 16 patentes). De forma ilustrativa, a Figura 1.3, apresenta apenas a patente 1 e 2 da lista de 16. Note, ainda, na Figura 1.3, os termos pesquisados

\footnotetext{
1 "A Classificação Internacional de Patentes (CIP), conhecida, também, pela sigla IPC - International Patent Classification, foi estabelecida pelo Acordo de Estrasburgo em 1971 e prevê um sistema hierárquico de símbolos para a classificação de Patentes de Inveção e de Modelo de Utilidade de acordo com as diferentes áreas tecnológicas a que pertencem. A IPC é adotada por mais de 100 países e coordenada pela Organização Mundial da Propriedade Intelectual - OMPI . » (INPI, 2013).
} 
II Congresso Brasileiro de Informática na Educação (CBIE 2013)

II Jornada de Atualização em Informática na Educação (JAIE 2013)

aparecem em sublinhado amarelo, indicando o casamento dos termos pesquisados com as patentes encontradas peloesp@cenet.

\begin{tabular}{|c|c|c|c|c|c|c|}
\hline & $\begin{array}{l}\text { Europäisches } \\
\text { Patentamt } \\
\text { European } \\
\text { Patent Office } \\
\text { Office européen } \\
\text { des brevets }\end{array}$ & \multicolumn{2}{|c|}{$\begin{array}{l}\text { Espacenet } \\
\text { Patent search }\end{array}$} & & & [ \\
\hline \multicolumn{6}{|c|}{ « About Espacenet Other EPO online services } & \\
\hline Search & Result list & $\star$ My patents list (0) & Query history & Settings & Help & \\
\hline
\end{tabular}

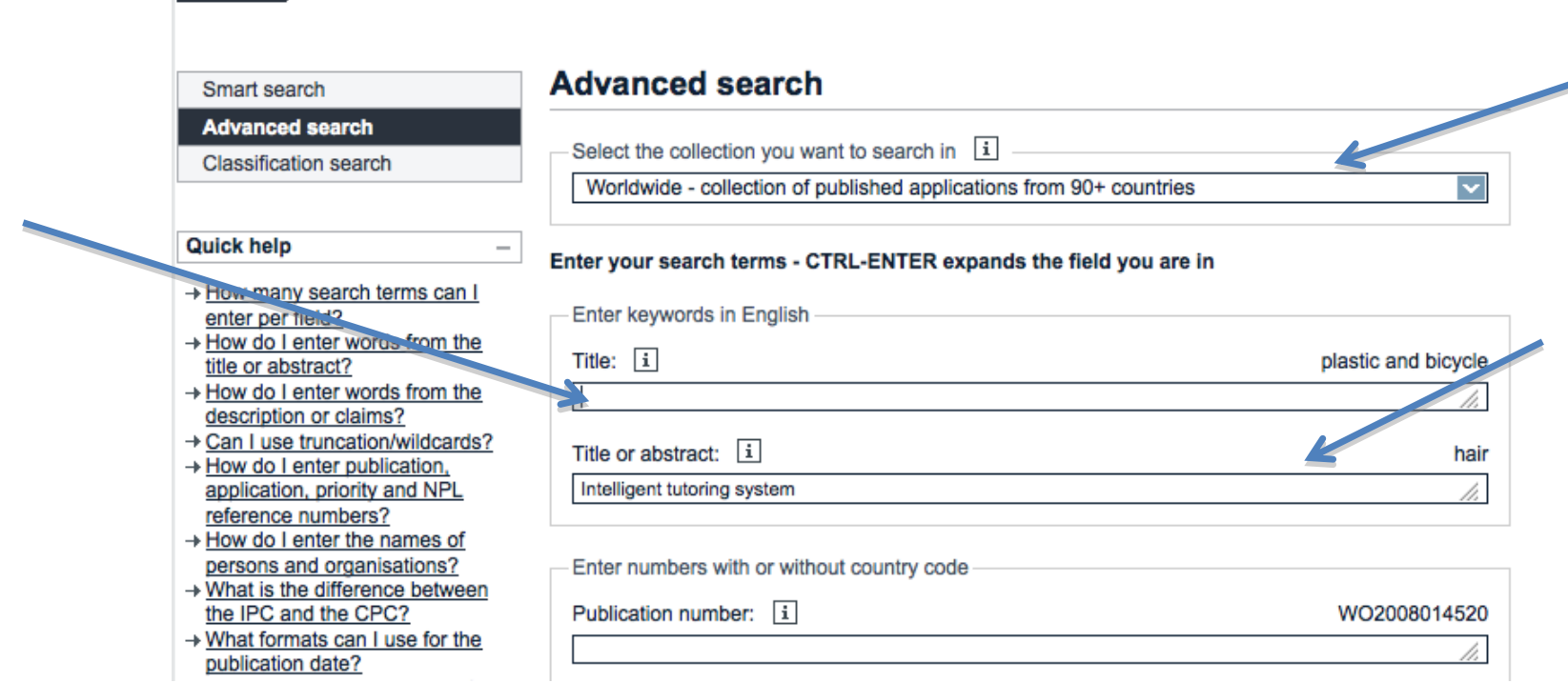

Figura 1.2. a busca avançada no esp@cenet

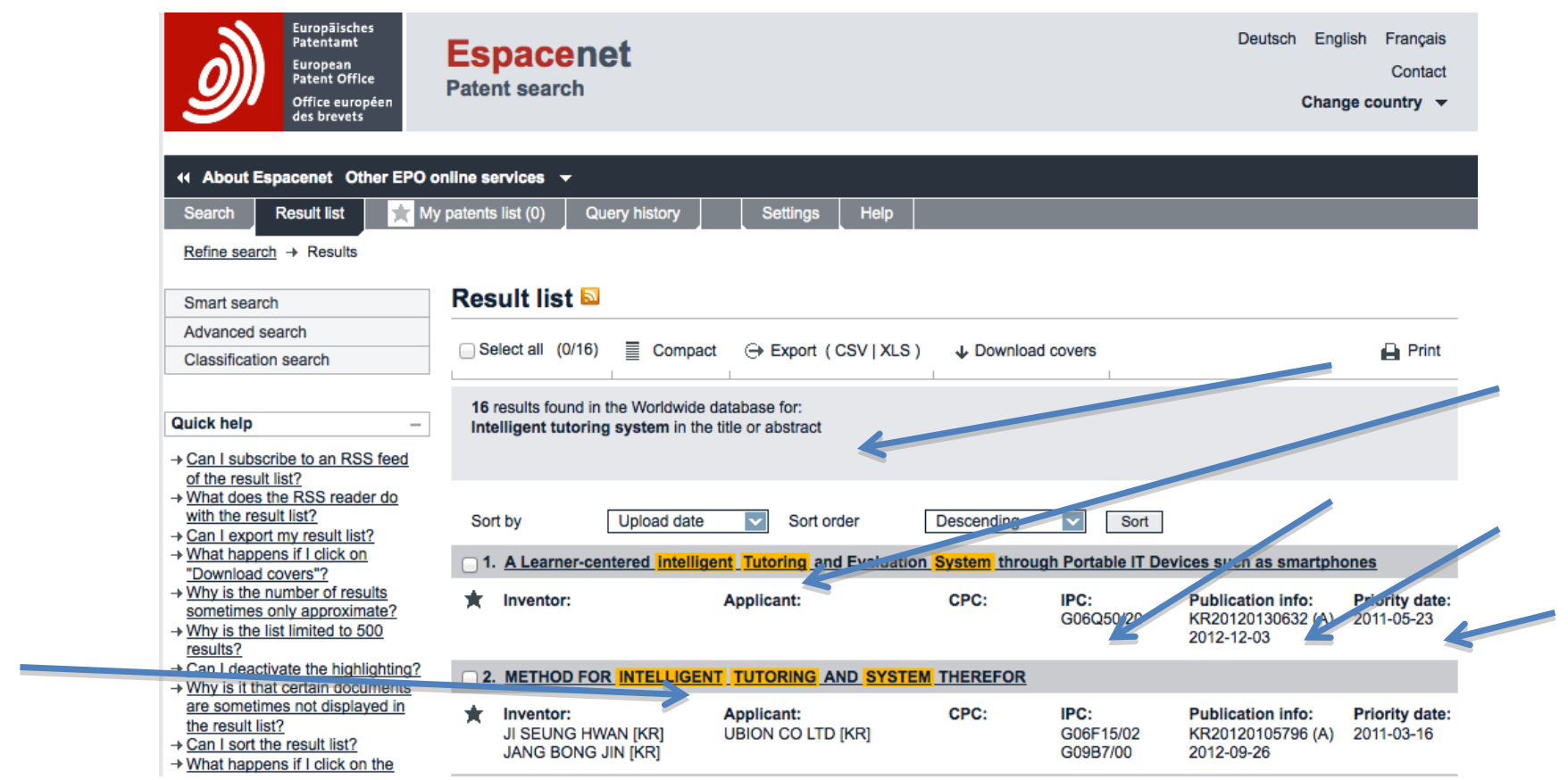

Figura 1.3. a lista de patentes encontradas como resultado da pesquisa avançada 
Note que, ainda na Figura 1.3, a cada item selecionado o usuário tem acesso aos dados básicos que identificam a patente, tais como: o nome do inventor (Inventor); o titular e depositante da patente (Applicant); o código IPC (CIP); data da publicação (publication info) (referente a 18 meses após o depósito da patente); a data de prioridade (priority date) (concedida caso o titular tenha depositado essa mesma tecnologia em outro país nos últimos 12 meses. Ele possui privilégio sob essa tecnologia frente a qualquer outro titular).

Para ilustrar, clicou-se na patente de número 2 da Figura 1.3, essa patente foi submetida por um titular coreano e inventor coreano (essa informação já existia também na Figura 1.3). A informação sobre a origem da patente pode ser obtida consultando-se as iniciais no número da patente. Por exemplo, na Figura 1.4, apresenta-se a número da patente $=$ KR20120105796, onde o KR significa Coreia.

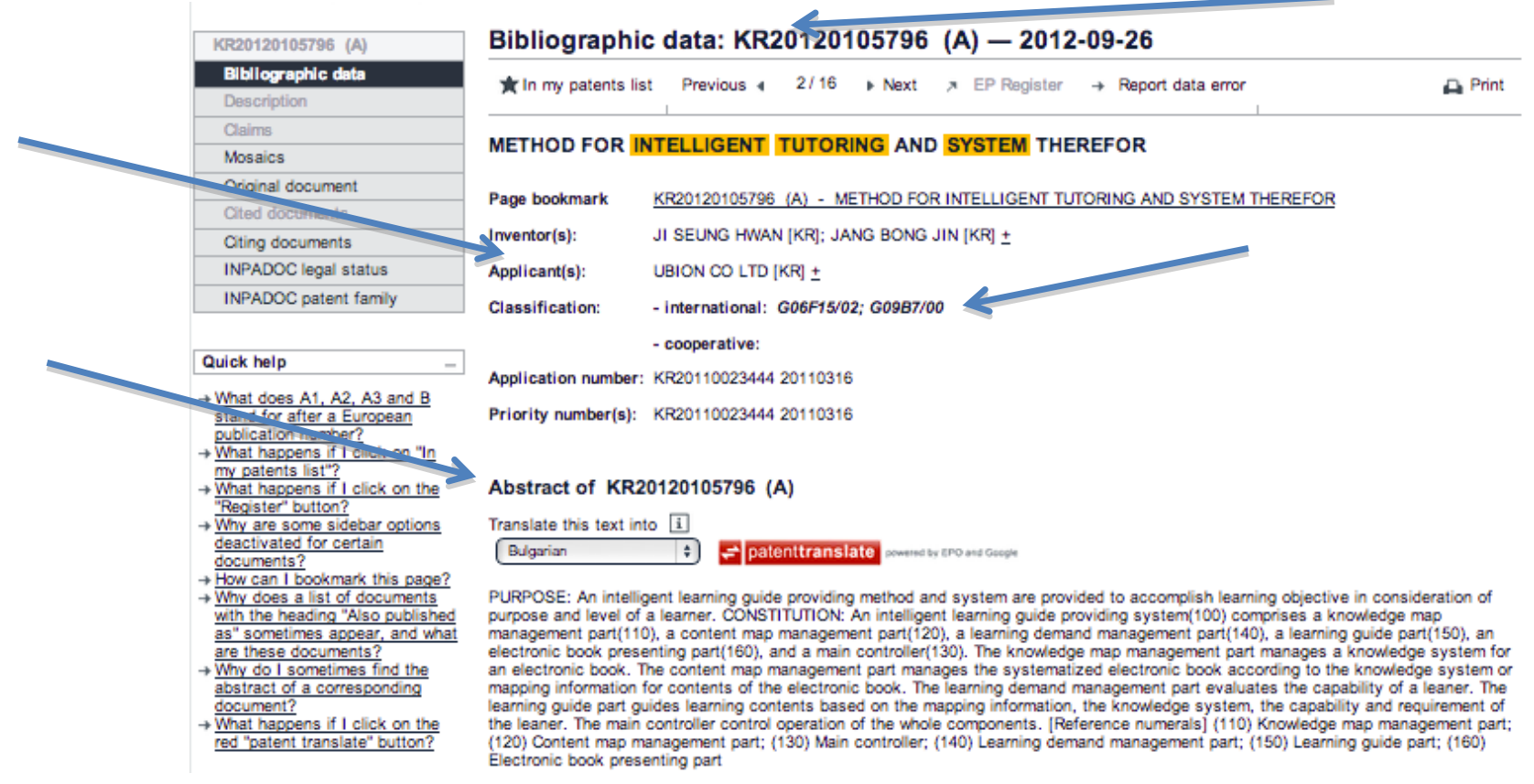

Figura 1.4. dados da patente selecionada após busca avançada por termo "inteligent tutoring system" no esp@cenet

A Coreia é cossignatária do $\mathrm{PCT}^{2}$ (a lista completa dos países cossignatários pode ser encontrada em PCT (2013)). Na Figura 1.4, a patente apresenta informações importantes, tais como: o abstract da patente e o IPC, além das outras informações já apresentadas na Figura 1.3 (referente aos inventores, aos titulares, ao número do depósito e ao número de prioridade). O abstract e o IPC são informações que melhor classificam a patente, no exemplo da Figura 1.4, os códigos IPCs da patente são referentes ao: (i) G06F15/02 (Computadores digitais em geral manualmente acionado com entrada pelo teclado e com a computação controlada por um programa incorporado (built-in)); (ii) G09B7/00 (Aparelhos ou dispositivos de ensino de funcionamento elétrico procedendo por perguntas e respostas). Note que na patente da Figura 1.4, o

\footnotetext{
2 PCT (Patent Cooperation Treaty): consiste em um tratado internacional, administrado pela OMPI (Organização Mundial de Propriedade Intelectual). Permite solicitar Propriedade Intelectual proteção para uma patente de invenção simultaneamente em vários países membros, depositando um único pedido "internacional" em lugar de vários pedidos nacionais ou regionais, segundo Russo et al. (2012).
} 
esp@cenet não fornece acesso ao documento de patente completo, como pode-se perceber que acontece em outra patente da lista gerada a partir do exemplo da Figura 1.5 .

A disponibilização de acesso ao documento da patente originária/oficial deve-se aos acordos EPO com os outros escritórios no mundo, como discutido anteriormente e disponível em EPO (2011). A Figura 1.5, diferentemente da Figura 1.4, apresenta o acesso à patente originária. Ao clicar no link "also published as" o pesquisador terá acesso ao documento de patente original e completo.

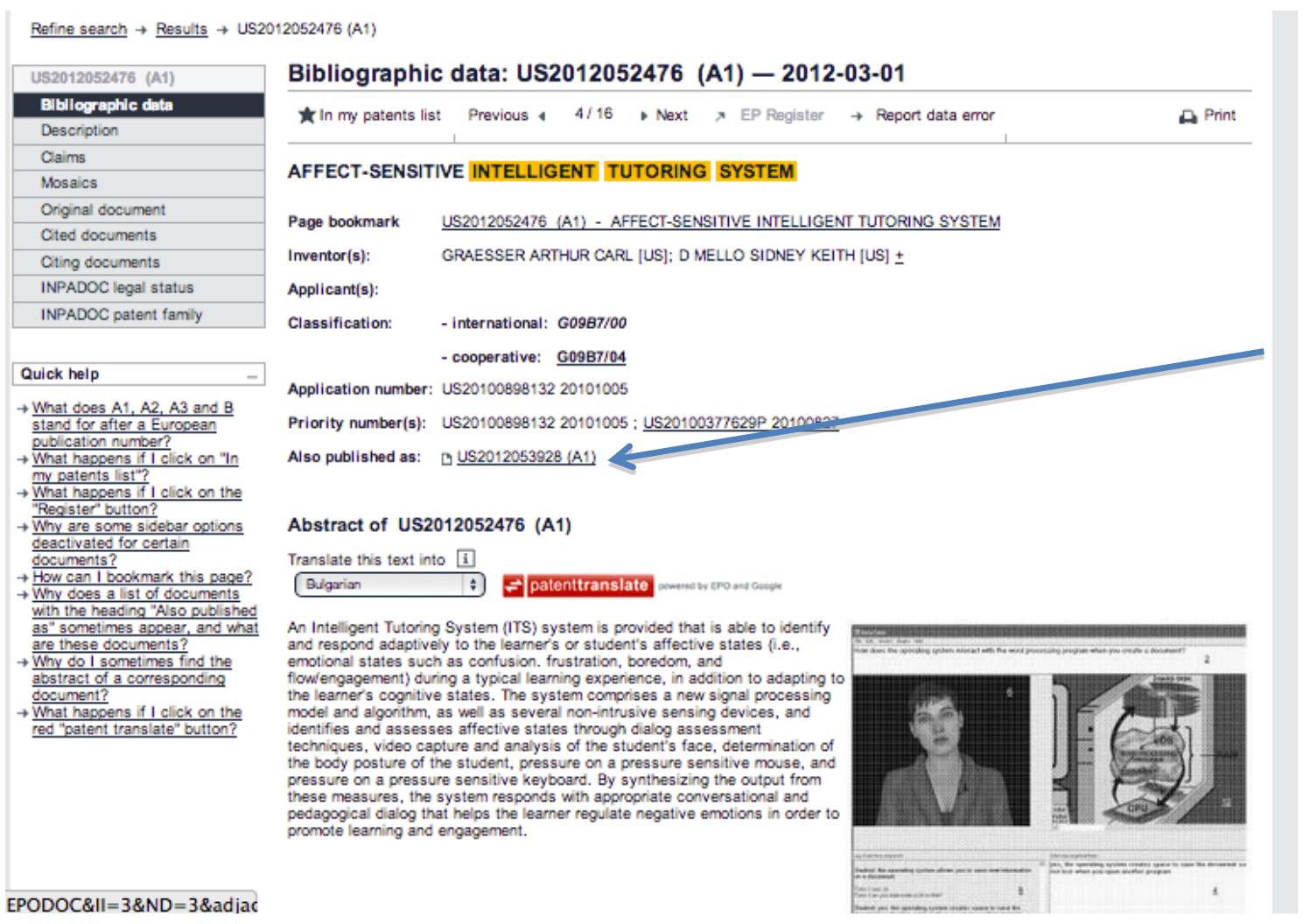

Figura 1.5. direcionamento à patente original via esp@cenet

\subsubsection{USPTO}

O USPTO é o órgão federal americano responsável pelos registros de patentes e marcas, de acordo com USPTO (2013). O USPTO possui uma base de mais de 7 milhões de patentes. O USPTO possui duas bases diferenciadas, uma relacionada as patentes concedidas (USPTO Patent Full-Text and Image Database (PatFT)) e a outra relacionada as patentes depositadas (USPTO Patent Application Full-Text and Image Database (AppFT)). No PatFT o usuário tem acesso às patentes americanas concedidas desde 1790, porém o acesso ao texto completo é possível somente para as patentes concedidas desde 1976. Já no AppFT o usuário tem acesso as patentes depositadas desde 2001. Na base USPTO o usuário pode realizar a busca usando os operadores booleanos and, or e and not. Também é permitido o uso do caractere de truncamento "\$" que substitui um número ilimitado de caracteres. O USPTO cobre todas as áreas de conhecimento e possui uma atualização semanal. 
Para realizar a busca no USPTO o usuário deve clicar no endereço http://www.uspto.gov/patents/ e selecionar o link "Patent search", como mostrado na Figura 1.6.

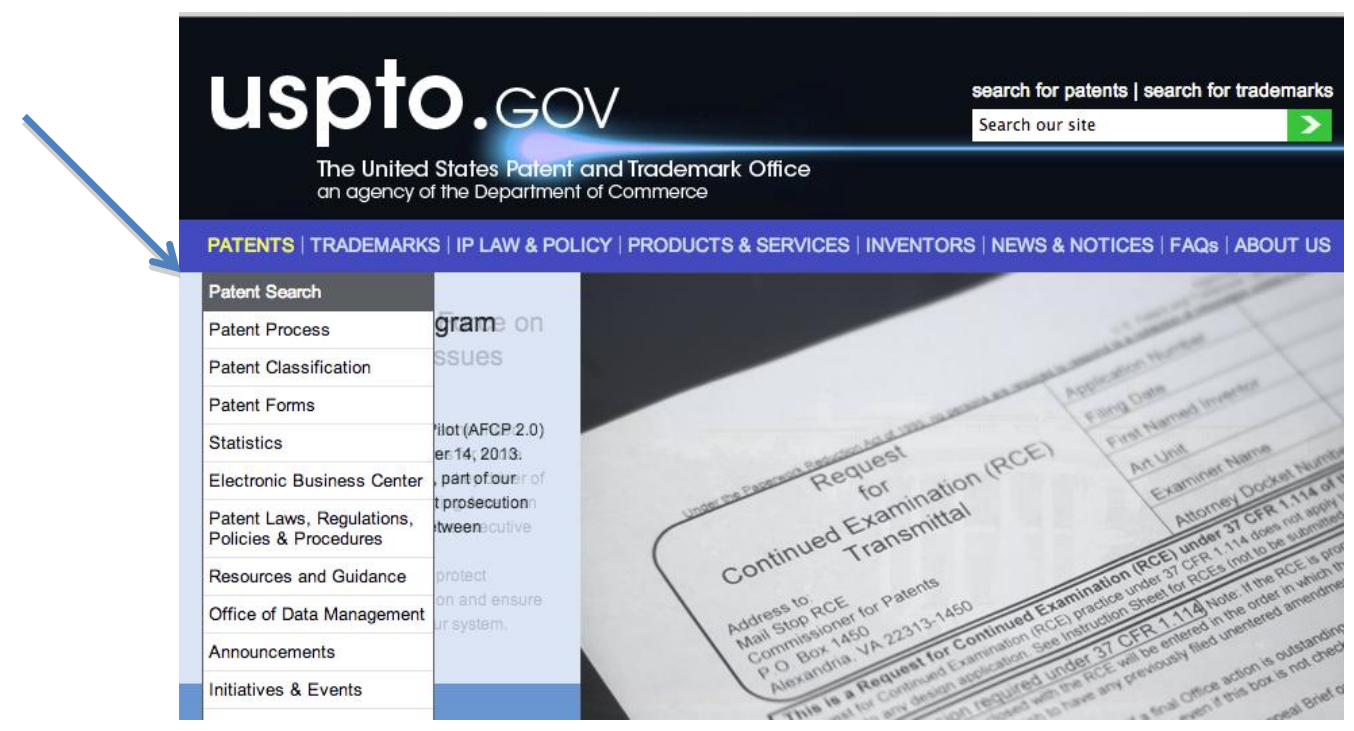

Figura 1.6. interface geral do USPTO

As buscas realizadas tanto no PatFT como no AppFT possuem interfaces avançadas e simples. Para que o usuário tenha acesso aos registros das patentes concedidas nos EUA ele deve selecionar a base PatFT com dados desde 1976, como mostrado na Figura 1.7.

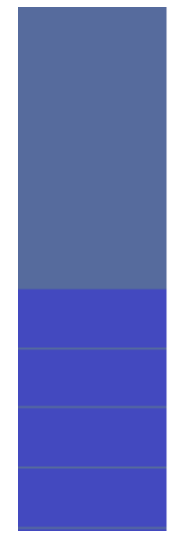

- Search Published Sequences

- Patent Assignment Database (Assignments on the Web)

\section{USPTO Patent Full-Text and Image Database (PatFT)}

Inventors are encouraged to search the USPTO's patent database to see if a patent has already $b$ similar to your patent. Patents may be searched in the USPTO Patent Full-Text and Image Databa houses full text for patents issued from 1976 to the present and PDF images for all patents from

\section{Searching Full Text Patents (Since 1976)}

Customize a search on all or a selected aroup fielements (fields) of a patent.

- Quick Search

- Advanced Search

- Patent Number Search

Searchina PDF Image Patents (Since 1790)

Figura 1.7. busca simples e avançada no PatFT - USPTO

As buscas avançadas são mais complexas de serem realizadas por pesquisadores iniciantes já que obrigam o uso de Query com operadores booleanos, como visto na Figura 1.8. Não existe facilidades para a procura de termos no título ou abstract da patente, como em outras bases. 


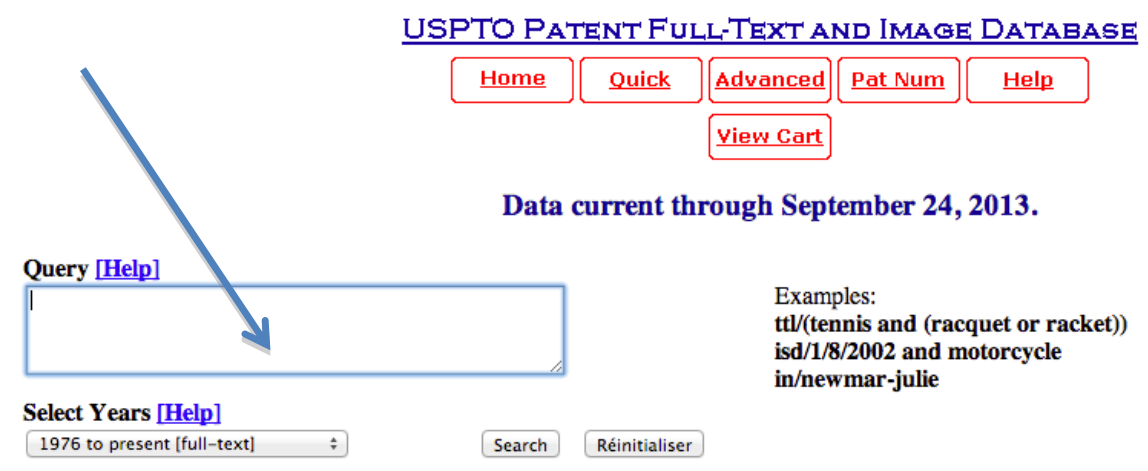

Patents from 1790 through 1975 are searchable only by Issue Date, Patent Number, and Current US Classification. When searching for specific numbers in the Patent Number field, patent numbers must be seven characters in length, excluding commas, which are optional.

\begin{tabular}{||l||l|||l||l||}
\hline $\begin{array}{c}\text { Field } \\
\text { Code }\end{array}$ & \multicolumn{1}{|c|}{ Field Name } & $\begin{array}{l}\text { Field } \\
\text { Code }\end{array}$ & \multicolumn{1}{c||}{ Field Name } \\
\hline \hline PN & Patent Number & IN & Inventor Name \\
\hline ISD & Issue Date \\
\hline TTL & Title & Inventor City \\
\hline \hline
\end{tabular}

Figura 1.8. busca avançada no PatFT- USPTO

A busca intitulada de "quick" na base USPTO, é caracterizada como a busca simples, e é apropriada ao pesquisador iniciante. Na Figura 1.9, como exemplo ilustrativo foi utilizado o mesmo termo do exemplo da busca anterior realizada no esp@cenet. A base USPTO permite o uso de apenas 2 termos (caso não use query) e apenas 2 campos, como, por exemplo, o título e o abstract, como visto na Figura 1.9.

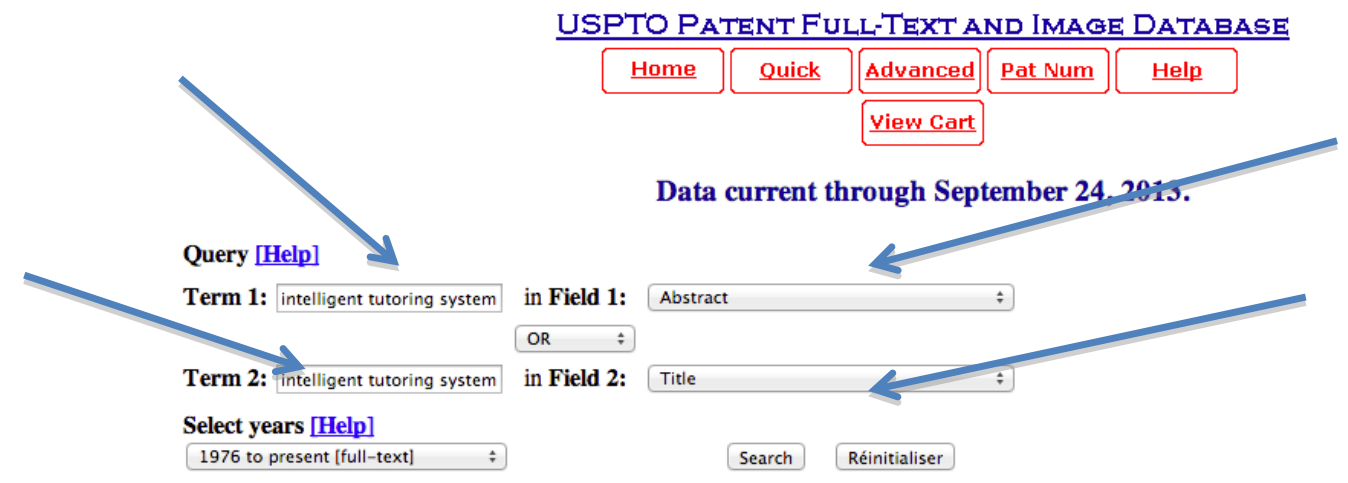

Patents from 1790 through 1975 are searchable only by Issue Date, Patent Number, and Current US Classification.

When searching for specific numbers in the Patent Number field, patent numbers must be seven characters in length, excluding commas, which are optional.

Figura 1.9. busca simples no PatFT - USPTO

O resultado da busca "quick" com os termos "Intelligent tutoring system" casados no abstract ou título, trouxeram apenas 4 patentes, como visto na Figura 1.10. O USPTO gerou um número de patentes bem menor que o esp@cenet, que gerou 16 patentes nessa mesma busca, como já informado na Figura 1.3. 


\section{USPTO PATENT FuLL-TEXT AND IMAGE DATABASE}

\begin{tabular}{|c|c|c|c|c|}
\hline Home & Quick & Advanced & Pat Num & Help \\
\hline & Bottom & View & art & \\
\hline
\end{tabular}

Searching US Patent Collection...

Results of Search in US Patent Collection db for:

ABST/"intelligent tutoring system" OR TTL/"intelligent tutoring system": 4 patents.

Hits 1 through 4 out of 4

Jump To

Refine Search ABST/"intelligent tutoring system" OR TTL/"intellị

PAT. NO.

Title

$1 \underline{8,356,997} \mathbf{T}$ Intelligent tutoring system

$2 \underline{6,807,535} \mathbf{T}$ Intelligent tutoring system

36 6,341,960 T Method and apparatus for distance learning based on networked cognitive agents

$4 \underline{6,014,134} \mathbf{T}$ Network-based intelligent tutoring system

Figura 1.10. resultados da busca USPTO para os termos Intelligent Tutoring system

Ao clicar em uma das 4 patentes resultantes da busca, o pesquisador tem acesso ao depósito da patente na integra no corpo do texto $\mathrm{html}$ da página. A legibilidade e organização do material na versão html da base USPTO não é muito convidativa, como mostra a Figura 1.11.

USPTO PATENT FULL-TEXT AND IMAGE DATABASE

\begin{tabular}{|c|c|c|c|c|}
\hline \multirow[t]{2}{*}{ Home } & Quick & Advanced & Pat Num & Help \\
\hline & Hit List & Next & Bottom & \\
\hline
\end{tabular}

United States Patent

$(1$ of 4

Bergeron

$8,356,997$

Intelligent tutoring system

January 22, 2013

Abstract

An intelligent tutoring system can be implemented using filters, predictive modeling, and a knowledge warehouse, which allows content to be

dynamically selected for individualized presentation to a learner. Such an intelligent tutoring system can be implemented using a variety of techniques, including polynomial vector equations in modeling, extensible markup language storage formats for presentation data, and a knowledge warehouse with information stored in data cubes.

Inventors: Bergeron; Bryan (Brookline, MA)

Applicant: Name City State Country Type

Figura 1.11. abrindo a patente via USPTO

Entretanto, o acesso via patente oficial em $p d f$ (Figura 1.12) é também oferecida ao clicar no link "images" (Figura 1.11), com uma legibilidade e apresentação muito melhor que a versão html. 


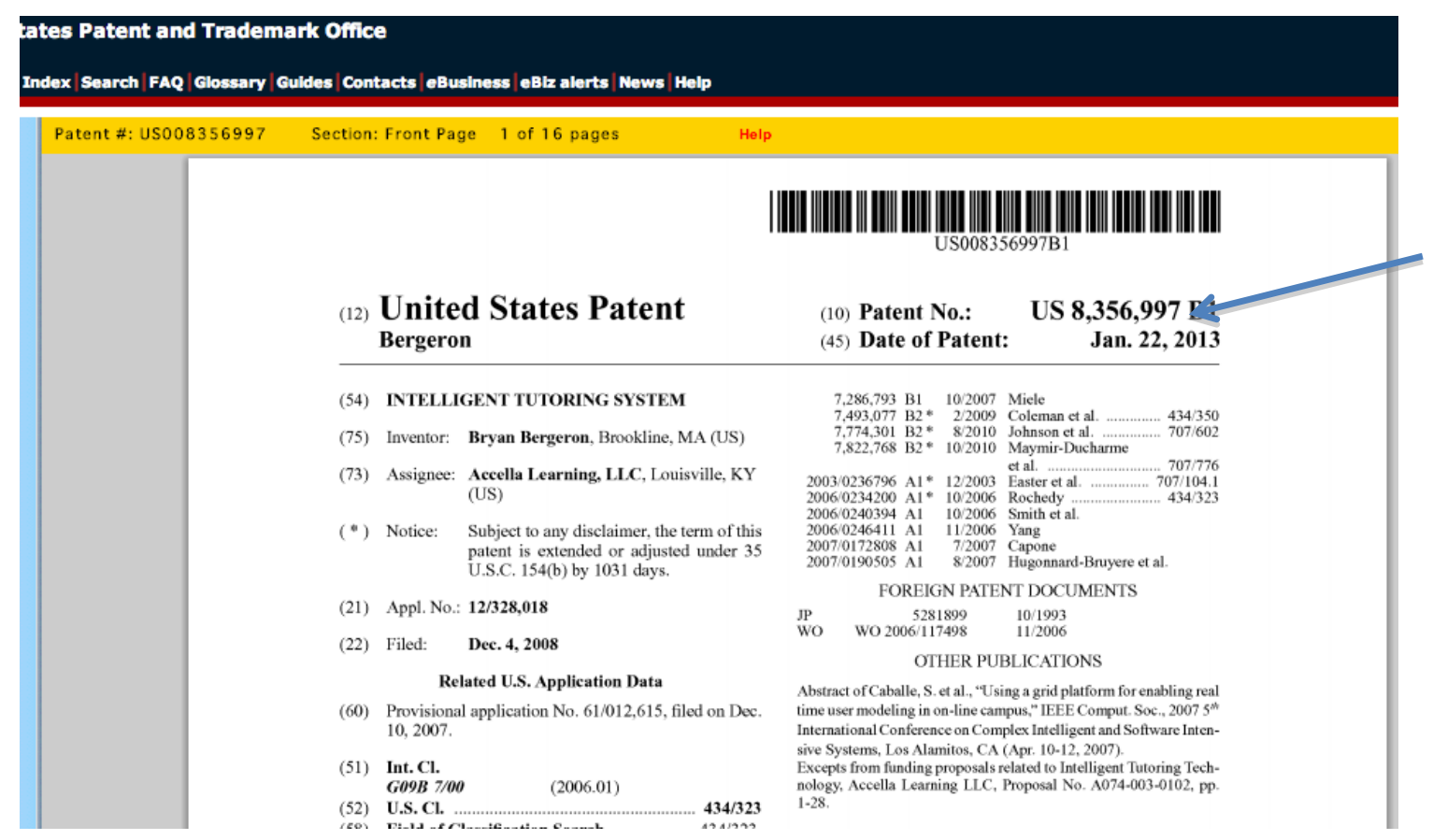

Figura 1.12. documento oficial da patente em pdf via USPTO

\subsubsection{WIPO}

O WIPO (World Intellectual Property Organization) ${ }^{3}$ é a agência das Nações Unidas (ONU) que se ocupa do uso da propriedade intelectual como meio de estimular a inovação e a criatividade, de acordo com WIPO (2013). A WIPO é uma das 17 agências especializadas da ONU, criada em 1967, com sede em Genebra. A WIPO possui atualmente 186 estados membros e administra 25 tratados internacionais, conforme WIPO (2013). A WIPO possui uma base de busca intitulada de PATENTSCOPE, cuja cobertura inclui registros de patentes oriundos de diversos escritórios de patentes no mundo. A base PATENTSCOPE possibilita a busca em aproximadamente 32,5 milhões de documentos de patente incluindo 2,2 milhões de patentes submetidas via $\mathrm{PCT}^{2}$.

O WIPO-PATENTSCOPE (2013) oferece na busca avançada uma cobertura detalhada por escritório parceiro mundial, como apresentado na Figura 1.13. Na busca avançada, o pesquisador pode ainda selecionar a língua oficial das patentes depositadas/concedidas, como mostrado na Figura 1.13. Existem ainda outras formas de buscas baseada em combinação de campo, e cruzamento de línguas, por exemplo.

A busca mais utilizada pelo pesquisador iniciante é a busca simples. Essa busca possibilita usar o termo pesquisado na primeira página do registro da patente "Frontpage", como apresentado na Figura 1.14. Essa característica de uso de termo na "Frontpage" difere um pouco da facilidade da busca com o uso de termos no título ou abstract do registro de patente, como realizado em outras bases. Na busca simples a pesquisa é realizada em todos os escritórios parceiros.

\footnotetext{
${ }^{3}$ Em português WIPO é chamado de OMPI (Organização Mundial da Propriedade Intelectual).
} 


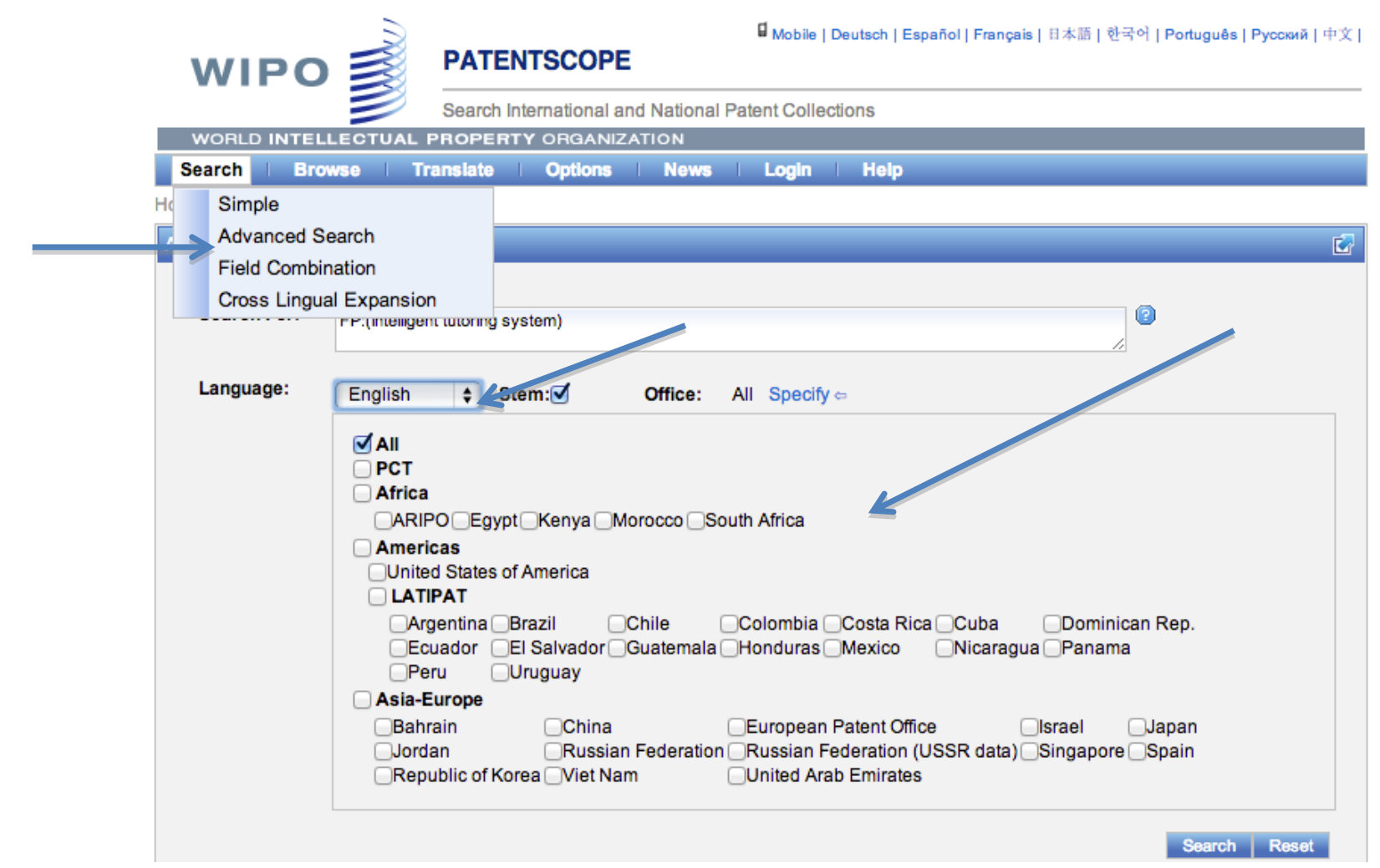

Figura 1.13. busca avançada via PATENTSCOPE WIPO

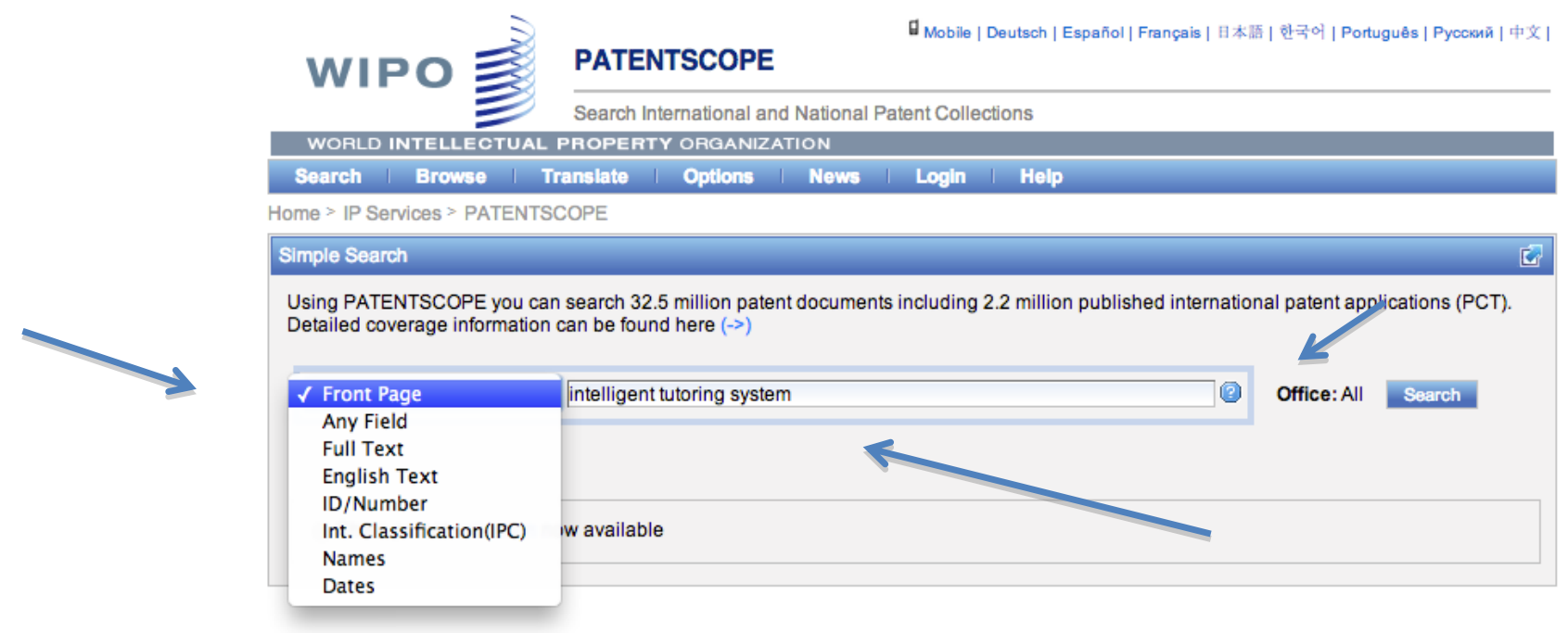

Figura 1.14. busca simples via PATENTSCOPE WIPO

A busca simples no PATENTSOPE considerando o mesmo cenário e termos das buscas anteriores realizadas no esp@cenet e USPTO, geraram 15 registros de patente no PATENTSCOPE, como visto na Figura 1.15.

A busca simples apresenta a listagem de registros de patente encontradas no casamento dos termos da busca. Cada registro de patente apresenta informações básicas sobre o país depositante, o número do registro de patente, o título, a data de publicação, a classificação internacional, o número do depósito, o nome do titular/depositante e o nome do inventor. Uma informação bastante útil e detalhada nessa fase da busca fornecida pela WIPO é a discriminação dissertativa do IPC. Na Figura 1.15, pode-se 
perceber a discriminação dissertativa do IPC no registro de patente, representado pelo G09B7.

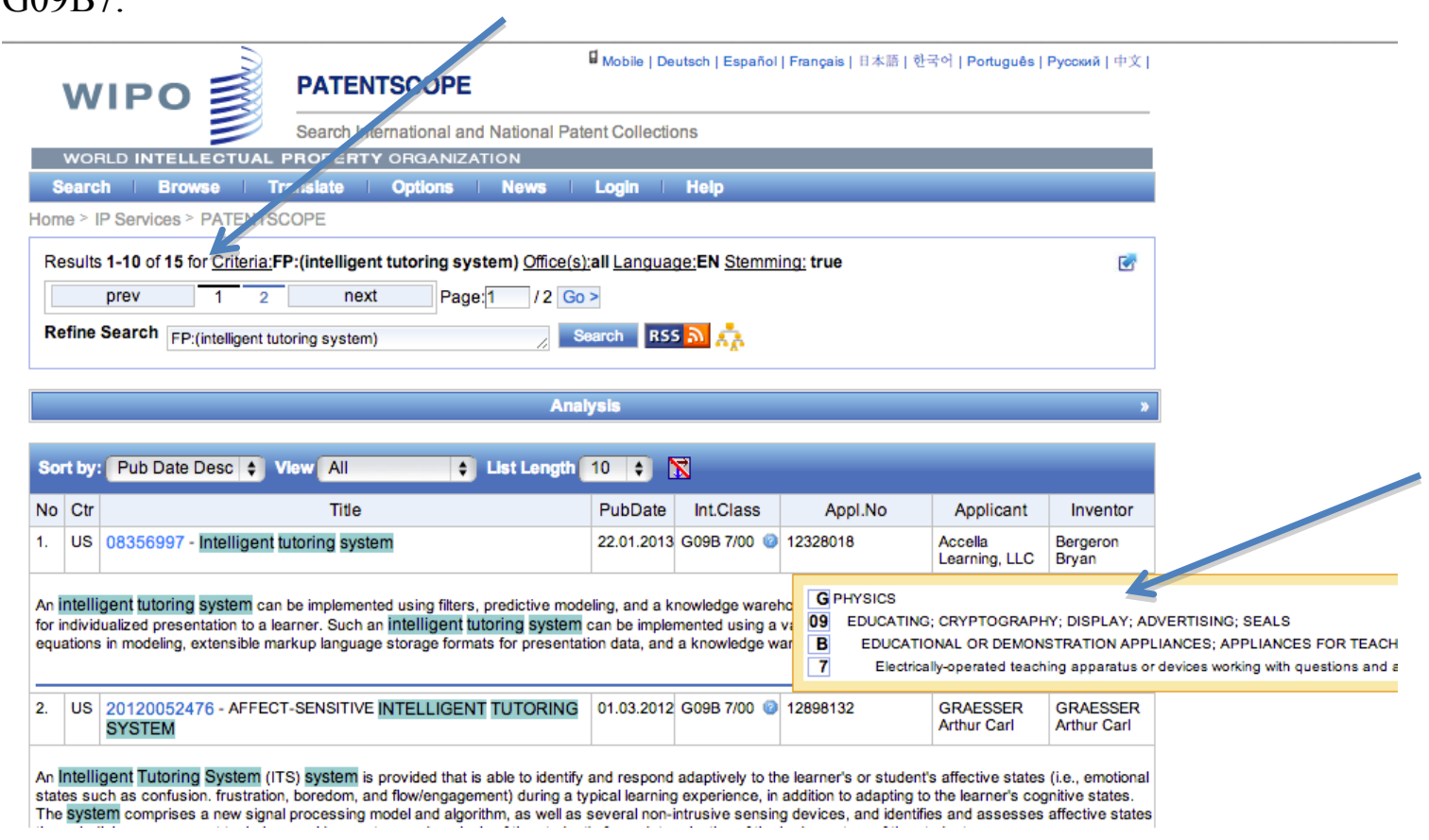

Figura 1.15. resultado da busca simples via PATENTSCOPE WIPO

Ao clicar-se no registro de patente escolhido (Figura 1.15), abre-se um conjunto maior de informações (Figura 1.16), incluindo diversas abas para informações detalhadas do processo, como, por exemplo: a National Biblio Data, relacionado aos detalhes do registro de patente; a descritption ou "descrição", com informações detalhadas sobre o conteúdo da patente; os claims ou "reivindicações"; os drawings ou "imagens" relativas à patente; os documentos disponibilizados por meio de um arquivo $x m l$-based relacionado ao registro da patente, possivelmente para facilitar a recuperação e uso por outros sistemas informatizados (de outros escritórios ou indexadores, por exemplo).

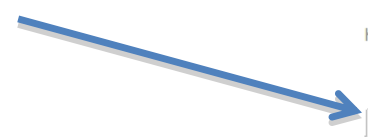

Home > IP Services > PATENTSCOPE

2. (US20120052476) AFFECT-SENSITIVE INTELLIGE. TUTORING SYSTEM

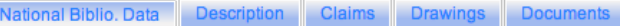

Permanent Link/Bookmark:

Application Number: 12898132 Application Date: 05.10.2010

Publication Number: 20120052476 Publication Date: 01.03.2012

Publication Kind : A1

IPC: $\quad$ G09B 7/00

Applicants: GRAESSER Artt G PHYSICS

Inventors: 09 EDUCATING; CRYPTOGRAPHY; DISPLAY; ADVERTISING; SEALS

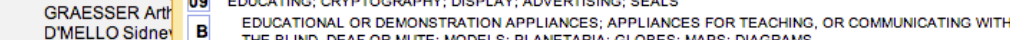

\begin{tabular}{llll}
\hline Pitle: & Electrically-operated teaching apparatus or devices working with questions and answe \\
\hline & (EN) AFFECT-SE & \\
\hline
\end{tabular}

Abstract: (EN)

An Intelligent Tutoring System (ITS) system is provided that is able to identify and respond adaptively to the learner's or student's affective states (i.e., emotional states such as confusion. frustration, boredom, and flow/engagement) during a typical learning experience, in addition to signal procsing model and algorithm, as well as several non-intusive sensing devices, and identifies and assesses affective states through dialog assessment techniques, video capture and analysis of the students face, determination of the body posture of the student, pressure on a pressure sensitive mouse, and pressure on a pressure sensitive keyboard. By synthesizing the output from these measures, the system responds with appropriate conversational and pedagogical dialog that helps the learner

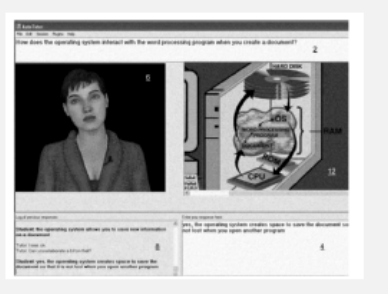

Figura 1.16. informações relacionadas à patente selecionada via busca simples 


\subsubsection{DERWENT}

O Derwent World Patent Index (2013) é uma base para busca de patentes paga. Criada e mantida pela Thomson Reuters, apresenta cobertura de mais de 47 autoridades de patentes do mundo, cobrindo mais de 47,8 milhões de documentos de patentes desde 1963. Essa base cobre especialmente a área tecnológica (Química, engenharias e eletroeletrônica). Uma das grandes facilidades do Derwent é que possui o link para textos completos de patentes disponíveis gratuitamente em outras bases. Permite a tradução das patentes para mais de 30 línguas. As buscas no Derwent permitem o uso de operadores booleanos e caracteres de truncamento, tal como : (i) *, para zero e muitos de caracteres; (ii) ? para um caractere e (iii) \# para zero ou um caractere exatamente. Exporta os documentos para vários formatos de saída.

Como as buscas via Derwent são pagas, no Brasil o acesso é disponibilizado por meio do Periódico CAPES via Web-of-Science (Thomson Reuters). Com caráter ilustrativo, foi realizada uma busca usando os mesmos termos já utilizados nos exemplos anteriores via esp@cenet, USPTO e WIPO. Os termos "Intelligent tutoring system" foram pesquisados no título e topic, como apresentado na Figura 1.17.

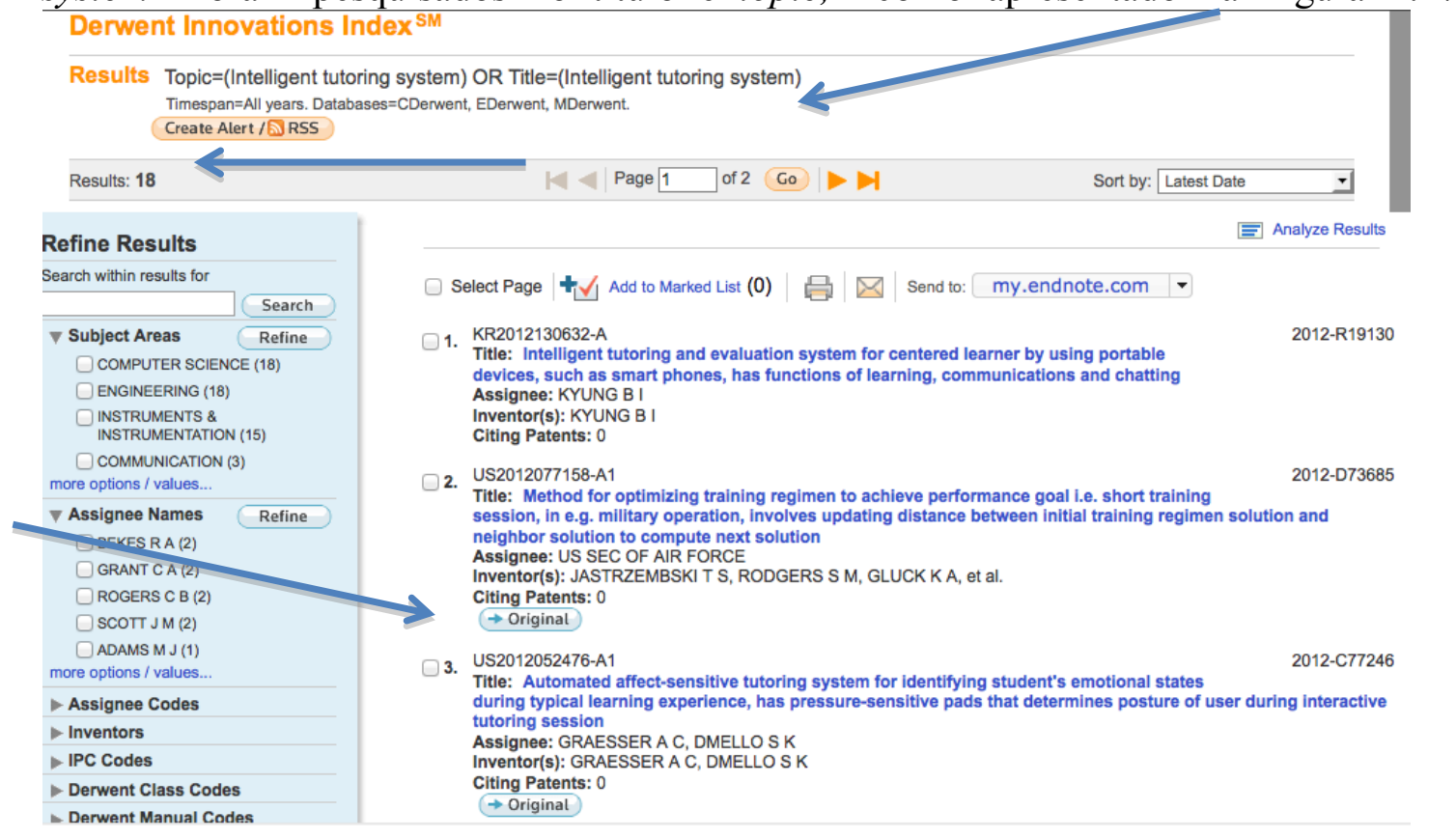

Figura 1.17. interface após a busca simples no Derwent

A interface do Derwent parece mais limpa e, de imediato, a interface remete o usuário à patente original do registro de patente, que pode ser armazenada. Foram encontrados 18 registros de patente com relação ao termo pesquisado no Derwent. Ao abrir um registro de patente, o usuário pode navegar pelos documentos informacionais dos registros de patentes encontrados na busca (Figura 1.18) sem necessitar voltar à interface original da busca (Figura 1.17). Na Figura 1.18, é também frisado o acesso imediato que o usuário tem ao documento $p d f$ original do registro de patente. Na Figura 1.18, ainda percebe-se, em amarelo, os termos solicitados na busca e casados pelo Derwent nos documentos de registro de patentes (no título e nos diferentes tópicos do registro). O registro de patente mostrado na Figura 1.18 remete à mesma tecnologia dos registros usados como cenário ilustrativo das bases esp@cenet, WIPO e Derwent citados anteriormente. No entanto, note que o título do registro da patente no Derwent 
está um pouco diferente que nas outras bases, porém o número do depósito continua o mesmo.

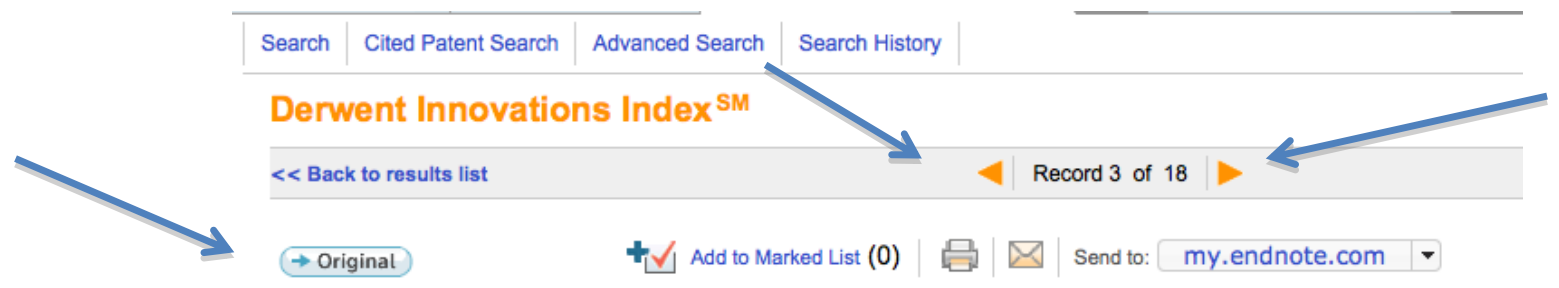

Automated affect-sensitive tutoring system for identifying student's emotional states during typical learning experience, has pressure-sensitive pads that determines posture of user during interactive tutoring session

Patent Number(s): US2012052476-A1

Inventor(s): GRAESSER A C, DMELLO S K

Patent Assignee Name(s) and Code(s): GRAESSER A C(GRAE-Individual) DMELLO S K(DMEL-Individual)

Derwent Primary Accession Number: 2012-C77246 [19]

Abstract: NOVELTY - The system has a computing device that is provided with a microprocessor, a keyboard, a computer mouse, a microphone that receives input from a user (18) and a non-transitory computer-readable storage medium with an executable program stored. The program in the storage medium is engaged with the user in an interactive tutoring session. The posture of the user is determined by the pressure-sensitive pads during the interactive tutoring session.

USE - Automated affect-sensitive tutoring system for identifying and responding to the learner's or student's emotional states such as confusion, frustration, boredom, and flow/engagement during typical learning experience.

ADVANTAGE - The system can scaffold learners to new levels of understanding through ideal patterns of emotions such as intellectual arousal, confusion combined with curiosity and moments of delight, while minimizing frustration, anger, and boredom, thus a unique learning environment is enhanced in tutorial interactions.

\section{Figura 1.18. apresentação dos detalhes de um registro de patente no Derwent}

A Figura 1.19 mostra o restante do documento referente à Figura 1.18 onde as informações detalhadas continuam a ser apresentadas.

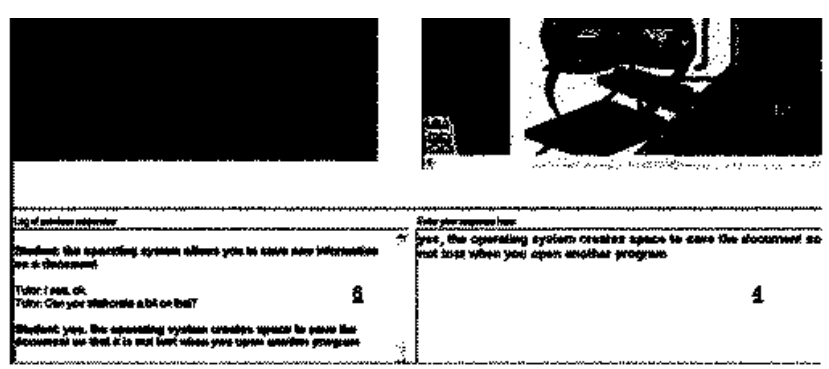

International Patent Classification: G09B-007/00

Derwent Class Code(s): P85 (Education, cryptography, adverts); T01 (Digital Computers); T04 (Computer Peripheral Equipment)

Derwent Manual Code(s): T01-J30A; T04-F02B1

Patent Details:

\begin{tabular}{|l|l|l|l|l|l|}
\hline Patent Number & Publ. Date & Main IPC & Week & Page Count & Language \\
\hline
\end{tabular}

\begin{tabular}{|l|l|l|l|l|l|}
\hline US2012052476-A1 & 01 Mar 2012 & G09B-007/00 & 201218 & Pages: 13 & English \\
\hline
\end{tabular}

Application Details:

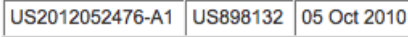

Further Application Details:

\begin{tabular}{|l|l|l|l|l|l|l|}
\hline US2012052476-A1 & Provisional & Application & US377629P \\
\hline
\end{tabular}

Priority Application Information and Date:

US377629P 27 Aug 2010

\begin{tabular}{|l|l|}
\hline US898132 & 05 Oct 2010 \\
\hline
\end{tabular}

Figura 1.19. continuação dos detalhes de um registro de patente no Derwent 
A busca no Derwent apresentou o maior número de registro de patentes referente ao termo pesquisado "Intelligent tutoring system" até o momento (Derwent $=18$; esp@cenet $=16 ; \mathrm{WIPO}=15 ; \mathrm{USPTO}=4$. Conclui-se que é a mais completa, porém é paga.

\subsubsection{INPI}

O INPI (Instituto Nacional de Propriedade Industrial) foi criado em 1970. É, atualmente, vinculado ao Ministério do Desenvolvimento, Indústria e Comércio Exterior (MDIC) no Brasil. O INPI é uma autarquia federal responsável pelo aperfeiçoamento, disseminação e gestão do sistema brasileiro de concessão e garantia de direitos de propriedade intelectual para a indústria, dentre eles: os registros de marcas, desenhos industriais, indicações geográficas, programas de computador e topografias de circuitos, as concessões de patentes e as averbações de contratos de franquia e das distintas modalidades de transferência de tecnologia, conforme INPI (2013).

O INPI possui sua base de busca que pode ser acessada via www.inpi.gov.br clicando em "patente" e em seguida em "busca", como apresentado na Figura 1.20.

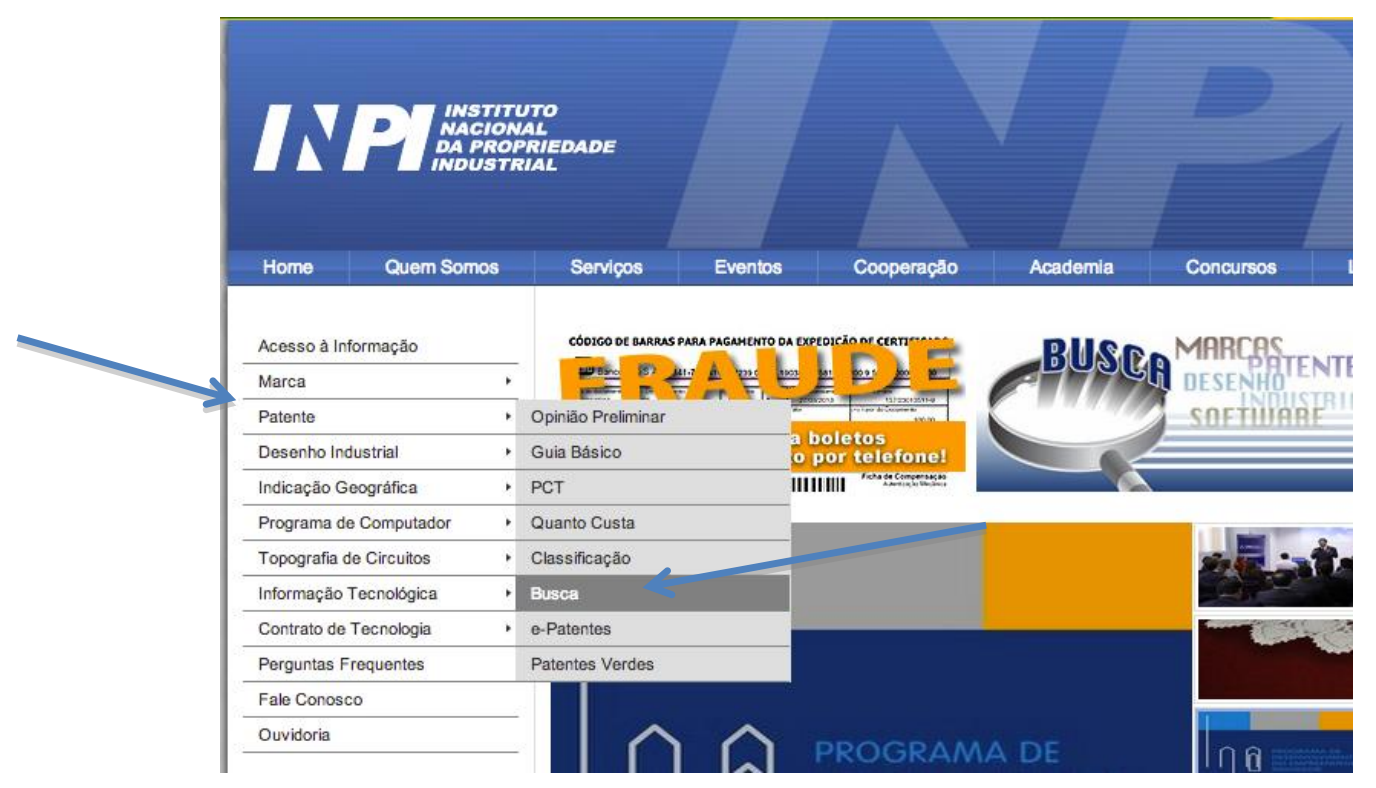

Figura 1.20. interface inicial do INPI

A busca pode ser realizada na base de patentes ou na base de programas, como apresentado na Figura 1.21.

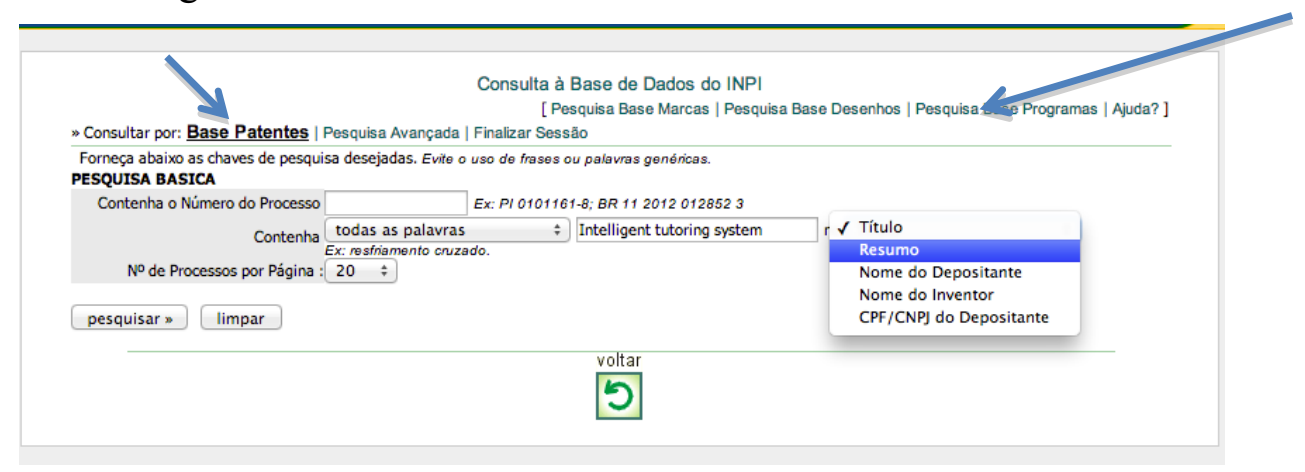

Figura 1.21. busca básica realizada na base de patentes do INPI 
Na Figura 1.21 apresenta-se a busca básica. As buscas no INPI apresentam pouca variação na combinação de termos, por exemplo, não existe a viabilidade de pesquisa pelo título + resumo, como realizada nas outras bases.

Em caráter ilustrativo, um busca básica foi realizada na base de patentes. Os termos das buscas foram os mesmos utilizados nas busca anteriores realizadas nas outras bases, nesse caso específico da busca no INPI, foi considerado tanto o termo em inglês como em português ("Intelligent tutoring system" ou "sistema tutor inteligente"). Como resultado da busca não foi encontrado nenhum registro na base de patentes, nem na base de programas. Dessa forma, o termo foi modificado para "personalidade", na base de patentes e na base de programas.

O resultado da busca na base de patentes, resultou em 47 processos de registros de patente com o uso do termo "personalidade" no resumo, como visto na Figura 1.22. A interface INPI apresenta apenas o número do processo, data de depósito e Título. Para ter acesso à mais informações sobre uma patente o pesquisador deve-se clicar em um processo desejado.

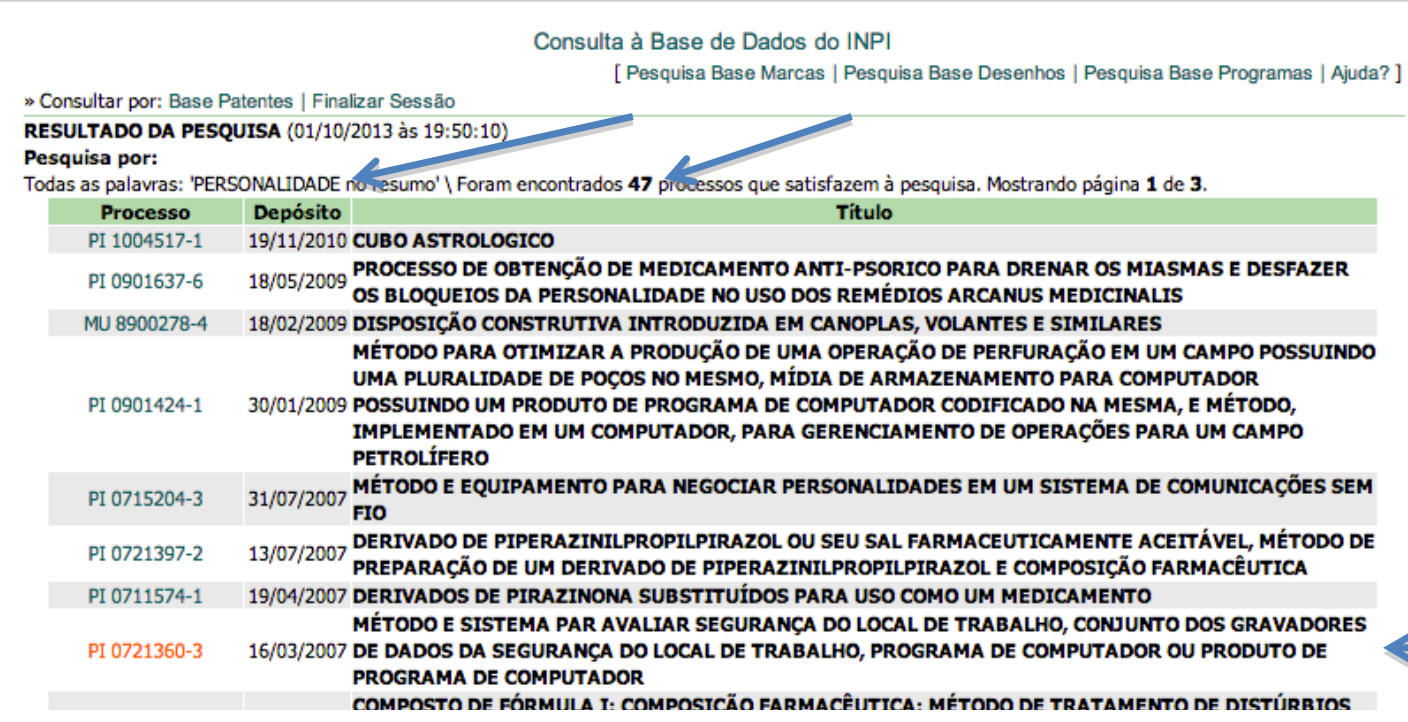

Figura 1.22. resultado da busca básica em patentes no INPI

Na Figura 1.22, selecionou-se a patente PI 0721360-3 (destacada em vermelho).

$\mathrm{Na}$ Figura 1.23, diversas informações relacionadas ao processo da patente são apresentados, dentre elas estão: número do pedido; data do depósito; IPC/CIP; título; resumo; nome do depositante; nome do inventor; procurador; datas das fases nacionais e internacionais (nos casos de PCT). Nessa interface o INPI apresenta também as informações relativas ao andamento do processo por meio das petições, que podem ser consultadas via link disponibilizado. O INPI também disponibiliza o acesso ao documento original, no link "leia-me antes", bem como a descrição do significado do IPC, como visto na Figura 1.23. 


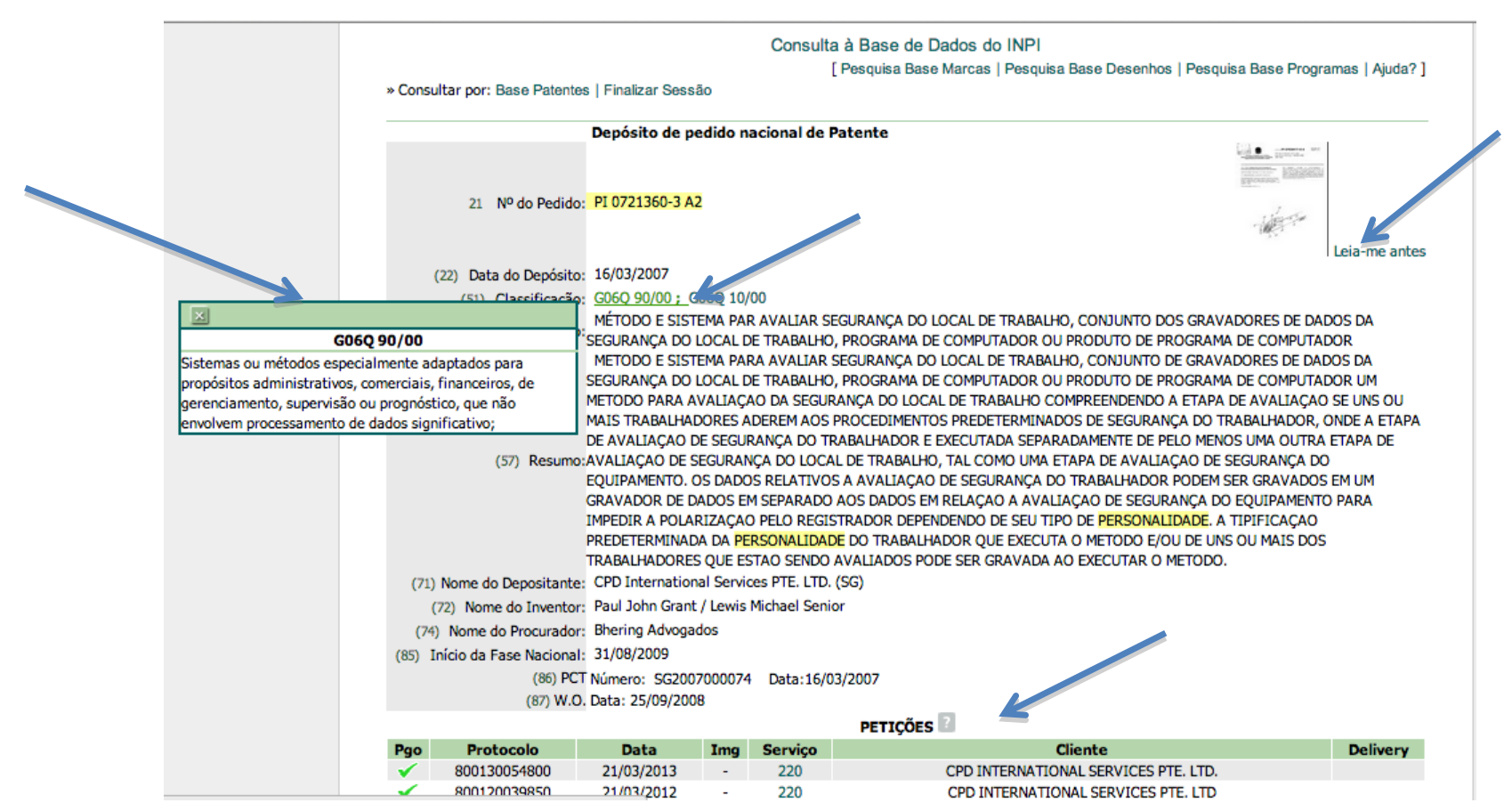

Figura 1.23. patente em detalhes via INPI

Como o INPI diferentemente das outras bases, possui uma base exclusivamente relacionada aos pedidos de registro de programa de computador. Foi realizada a busca do termo "personalidade" também na base de programas, como apresentado na Figura 1.24 .

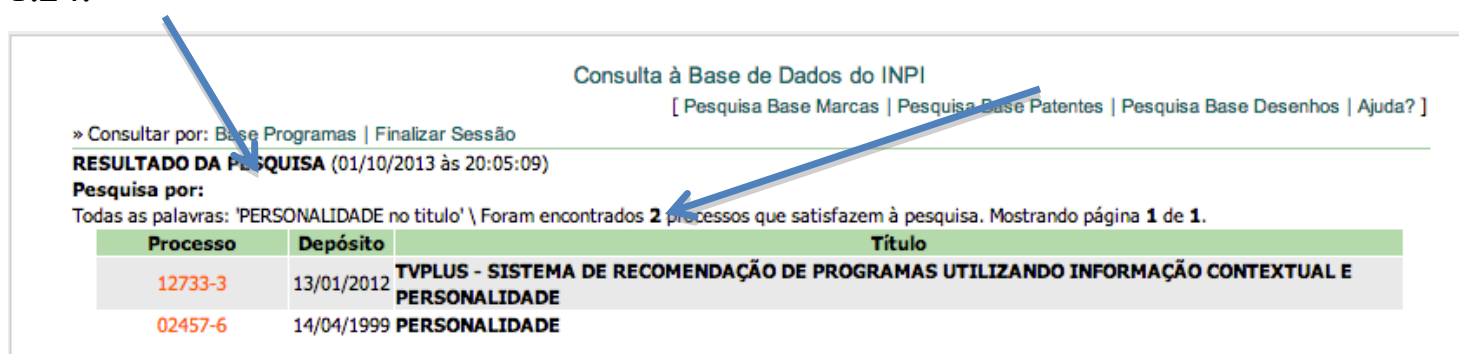

Figura 1.24. resultado da busca na base de programas no INPI

Foram encontrados 2 registros após a busca, da mesma forma que na busca de patentes, a busca de programas apresenta uma interface de resultados com poucas informações. Para o acesso à documentação complementar deve-se selecionar um processo, em caráter ilustrativo selecionou-se o processo 12733-3.

$\mathrm{Na}$ Figura 1.25, diversas informações relacionadas ao registro do programa de computador são apresentados, dentre elas estão: número do pedido; data de depósito; linguagem de programação; campo de aplicação; tipo de programa; título; titular; autor; procurador e petições sobre o andamento do processo. O INPI disponibiliza, ainda, de forma interativa, o significado das informações que indicam o campo de aplicação e o tipo de programa, como mostrado na Figura 1.25. 


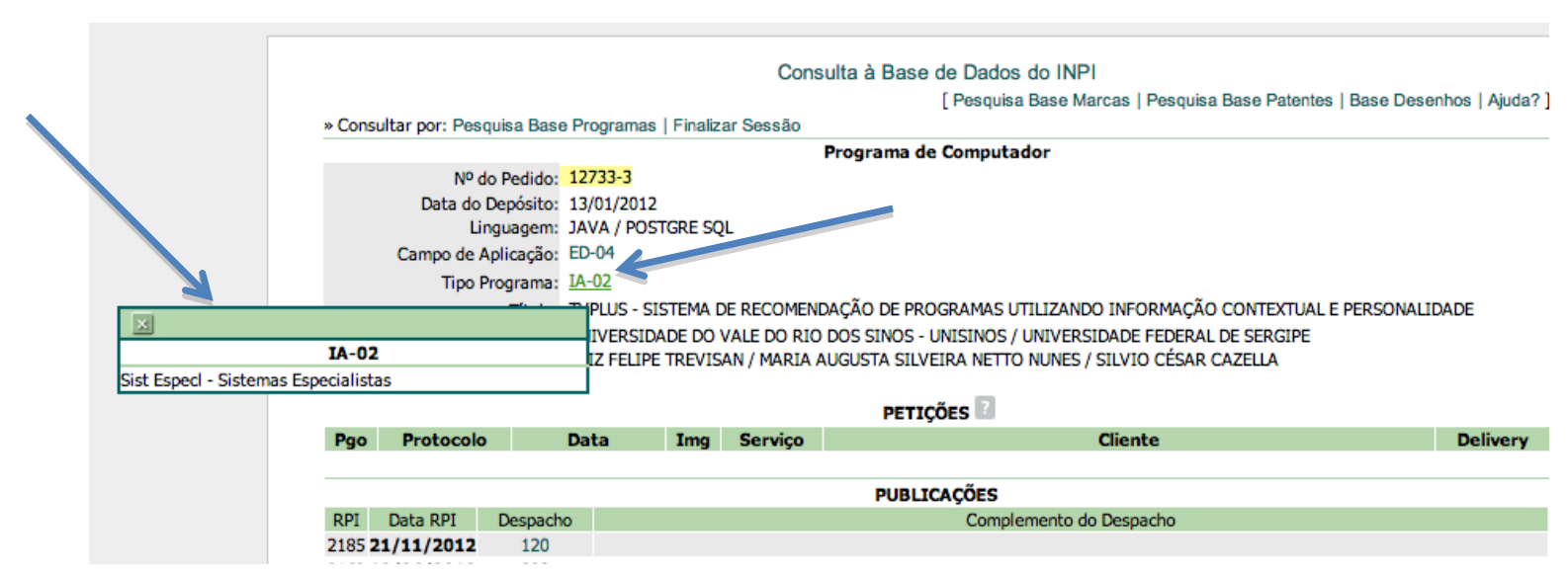

Figura 1.25. programa em detalhes via INPI

\title{
1.3.2. Operacionalização das busca e a construção da prospecção do produto
}

Após o conhecimento sobre o funcionamento operacional das bases de busca, o pesquisador de posse de conhecimentos sobre sua tecnologia tem condições de prospectar seu produto, traçando, assim, os possíveis mercados emergentes. Como na área de Ciência da Computação e/ou Informática na Educação os acadêmicos desconhecem como escrever um artigo de prospecção, os mesmos podem utilizar-se de modelos em periódicos brasileiros, tal como a GEINTEC $^{4}$ e os Cadernos de Prospecção ${ }^{5}$. Entretanto, as buscas que caracterizam a principal estratégia dissertativa de um artigo de prospecção, a partir de agora, o pesquisador já estará apto a realizar.

\subsection{Propriedade intelectual em Informática na Educação}

Após instrumentalizar o pesquisador em como em operacionalizar a busca e prospecção gerando um perfil mercadológico para sua tecnologia e seu posicionamento frente a outras tecnologias no mercado, é necessária, também, a etapa de apropriação dessa mesma tecnologia pelos acadêmicos e instituição onde o produto foi concebido. Para a devida apropriação da tecnologia o pesquisador deve conhecer a legislação brasileira e internacional sobre propriedade intelectual relacionada à essa tecnologia produzida.

\subsubsection{Introdução à propriedade intelectual e propriedade industrial}

Segundo Quintella (apud Russo et al. (2012b)), propriedade intelectual é :

\begin{abstract}
um conjunto de direitos que incidem sobre a criação do intelecto humano. Trata-se de um termo genérico utilizado para designar os direitos de propriedade que incidem sobre a produção intelectual humana (coisa intangível, ativo intangível), nos domínios industrial, científico, literário e artístico, assegurando ao titular o direito de auferir recompensa pela própria criação, por determinado período de tempo, Russo et al. (2012b).
\end{abstract}

Conforme exposto pela WIPO, a propriedade intelectual está estabelecida em duas categorias: (i) propriedade industrial e (ii) direitos autorais. A primeira inclui patentes, marcas, desenhos industriais e indicações geográficas. A segunda inclui obras literárias e artísticas (romances, poemas, peças de teatro, filmes, obras musicais,

\footnotetext{
${ }_{5}^{4} \mathrm{http}: / /$ www.revistageintec.net/

${ }^{5}$ http://www.redenit-ne.net/ojs-2.3.0/index.php/
} 
trabalhos artísticos, como desenhos, pinturas, fotografias e esculturas e projetos arquitetônicos) e programas de computador.

Neste capítulo a propriedade intelectual em Informática na Educação tratada com maior ênfase, são os programas de computador. Entretanto, existem vários outros ativos passíveis de registro e proteção, tal como objetos de aprendizagem, recursos educacionais abertos, tecnologias educacionais, recursos de acessibilidade, páginas web, blogs, marcas, entre outros.

\subsubsection{Tipos de proteções, legislação e registros de PI}

\subsubsection{Propriedade Intelectual em Software}

\section{Registro de Programa de Computador}

O Registro de Programa de Computador é uma das formas disponíveis no Brasil para conceder a autoria e, consequentemente, garantir a exclusividade na produção, uso e comercialização de um software, segundo Russo et al. (2012b). Este registro está estabelecido no regime jurídico do Direito Autoral, protegendo assim o ativo intelectual do desenvolvedor, conforme RS (2013).

Oficialmente, no Brasil, o Registro de Programas de Computador é competência do INPI (2013). As normas/leis para oficializar o Registro de Programa de Computador no INPI foram atribuídas pelo Decreto 2.556/98, de 20 de abril de 1998; pela Lei $\mathrm{n}^{\mathrm{o}}$ 9.609/98, de 19 de fevereiro de 1998, conhecida como Lei do Software; e pela Lei $\mathrm{n}^{\circ}$ 9.610/98, de 19 de fevereiro de 1998, a Lei de Direito de Autor." De acordo com Russo et al. (2012b). A Lei do Direito do Autor - LEI No 9.610, DE 19 DE FEVEREIRO DE 1998- LDA (1998) altera, atualiza e consolida a legislação sobre direitos autorais e dá outras providências.

O Programa de Computador é protegido como obra literária, isto é, o objeto de proteção é seu código fonte. Sua funcionalidade não pode ser protegida segundo a legislação. Isso significa que, ao registrar um programa de computador, é o código implementado que está sendo protegido. Já as funcionalidades e finalidades do mesmo, por suas naturezas intangíveis, não podem ser matérias de proteção isoladas no Brasil.

A Lei de Software - LEI No 9.609, DE 19 DE FEVEREIRO DE 1998 - LS (1998) frisa que, à luz da legislação brasileira, a parte protegida do Programa de Computador é o trecho do programa, ou seja, o código, ou parte dele. Como o Programa de Computador é protegido pela lei do Direito Autoral e, dessa forma, ele compreende os Direitos Morais, que são inalienáveis e irrenunciáveis, e os Direitos Patrimoniais. O prazo de validade dos Direitos Autorais no caso do Registro de Software é de 50 anos contados do dia $1^{\circ}$ de janeiro do ano subsequente à sua publicação ou, na ausência dessa informação, a data de criação do Programa, garantido o sigilo, se desejado, das partes do programa trazidas a registro no INPI. O sigilo é mantido por 10 anos e prorrogado se solicitado pelo titular, conforme Russo et al. (2012b).

O criador de um Programa de Computador deve ser uma pessoa física ou um grupo de pessoas. $\mathrm{O}(\mathrm{s})$ criador(es) pode(m) ser o(s) titular(es). Entretanto, o(s) titular(es) pode(m) ser uma (ou mais) pessoa(s) física(s) ou jurídica(s) (ou um grupo delas) que comprou(aram) o direito de exploração da obra (comprovado através do documento de cessão de transferência de direitos ou de comprovação de vínculo 
(empregatício ou prestação de serviços) com a empresa. O Registro de Programa de Computador não é obrigatório, porém em caso de disputa legal, o registro é uma forma de provar a autoria do Programa. A validade territorial do direito conferido ao titular do registro de Programa de Computador é reconhecido internacionalmente pelos países que assinaram o TRIPS (2012) e desde que seja cumprida a legislação nacional.

Como é feito o depósito do pedido de registro?

Segundo Neto e Nunes (2013), o pedido de registro realizado junto ao INPI é composto por: (i) Documentação Formal é relativa à auditoria e à titularidade do programa e; (ii) Documentação Técnica, constitui a documentação do programa em si. Os passos para realização do depósito do pedido são: (i) Geração e pagamento da Guia de Recolhimento da União - GRU; (ii) Preparação da Documentação Formal; (iii) Preparação da Documentação Técnica; (iv) Apresentação do pedido junto ao INPI; (v) Acompanhamento do processo. De posse da documentação (formal e técnica) o depositante poderá efetuar o depósito do pedido de registro na sede do INPI (conforme endereço fornecido no site INPI) ou em escritório do órgão em seu estado (conforme lista de endereços das representações fornecida no site INPI). Ou, ainda, o depósito pode ser realizado por via postal, com aviso de recebimento - AR. Por fim, como acontece em todos os trâmites de pedidos no INPI, o depositante pode acompanhar o processo através da Revista Eletrônica de Propriedade Industrial - RPI, disponível no site do órgão. Caso o depositante seja oriundo de uma instituição que possua NIT, o processo será facilitado por esse órgão.

\section{Software Público Brasileiro}

Segundo o discutido em Neto e Nunes (2013), o Software Público Brasileiro - SPB (2011) é definido pela instrução normativa $\mathrm{N}^{\mathrm{o}}$ 01, de 17 de janeiro de 2011, através da Secretaria de Logística e Tecnologia da Informação do Ministério do Planejamento e Gestão - SLTI/MP - SPB (2011). Conforme descrito no Portal do Software Público Brasileiro, disponível na Internet, segundo SPB (2011), o SPB adota um modelo de licença livre para o código-fonte aliado à proteção da identidade original entre o seu nome, marca, código-fonte, documentação e outros artefatos relacionados. Isto é garantido por meio do modelo de Licença Pública de Marca (LPM), conforme SPB (2011). A LPM é a formalização de um instrumento que libera o programa de computador e seus correlacionados (Marca, Nome e Artefatos) nas diretrizes do Software Livre e garante os direitos de autoria na forma do Registro.

\section{Como é feita a disponibilização do SPB?}

Para disponibilização do SPB no portal, alguns requisitos técnicos e jurídicos precisam estar contemplados. Entre os mais importantes estão: (i) Versão do software com instalação e uso estáveis; (ii) Manual; (ii) Código fonte; (iv) Scripts e bibliotecas requeridas; (v) Especificação no cabeçalho dos arquivos-fonte da Licença Pública Geral - GPL; (vi) Uso da LPM; (vii) Registro do software no INPI; (viii) Existência de responsáveis (coordenadores) do projeto. O Portal do Software Público Brasileiro na internet funciona como o canal de comunicação, por onde, qualquer pessoa, física ou jurídica, pode ofertar ou obter um SPB. Para ofertar, ou seja, colocar o um programa como um SPB, antes de tudo, é importante que o ofertante tenha conhecimento sobre a Instrução Normativa 01/2011 e também sobre o Manual do Ofertante, ambos disponíveis no site para download. Neste documento estão especificados todos os 
detalhes necessários à oferta do software. As Figuras 1.26 A e $\mathrm{B}$ mostram respectivamente os fluxos de oferta e solicitação do SPB (2011):

(A)

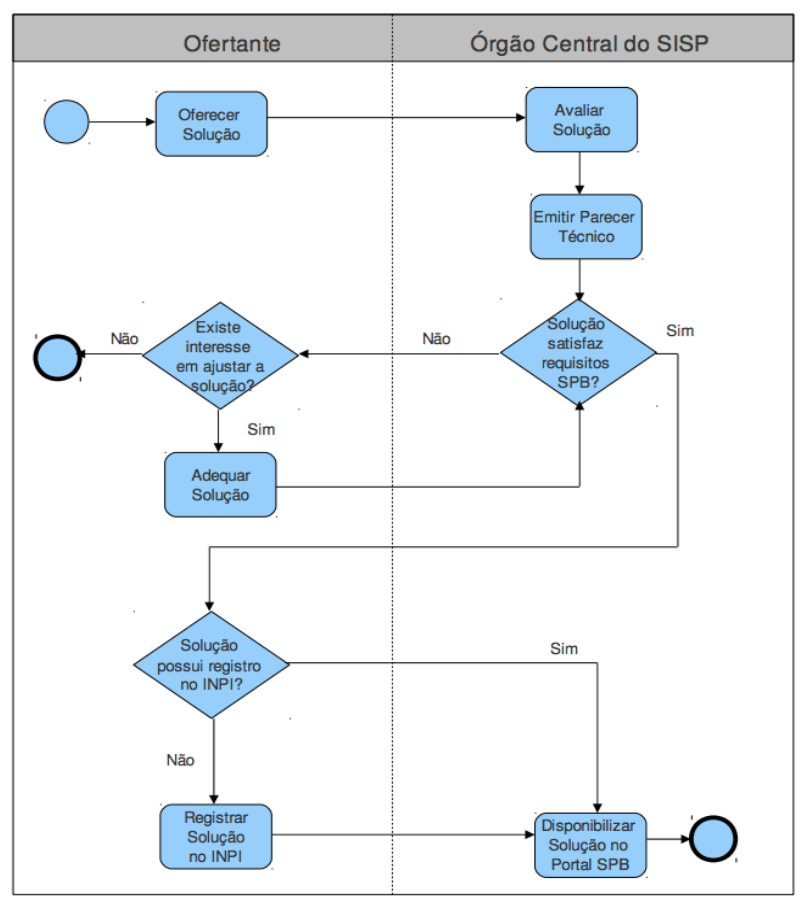

Fonte: extraído do SBP (2011)
(B)

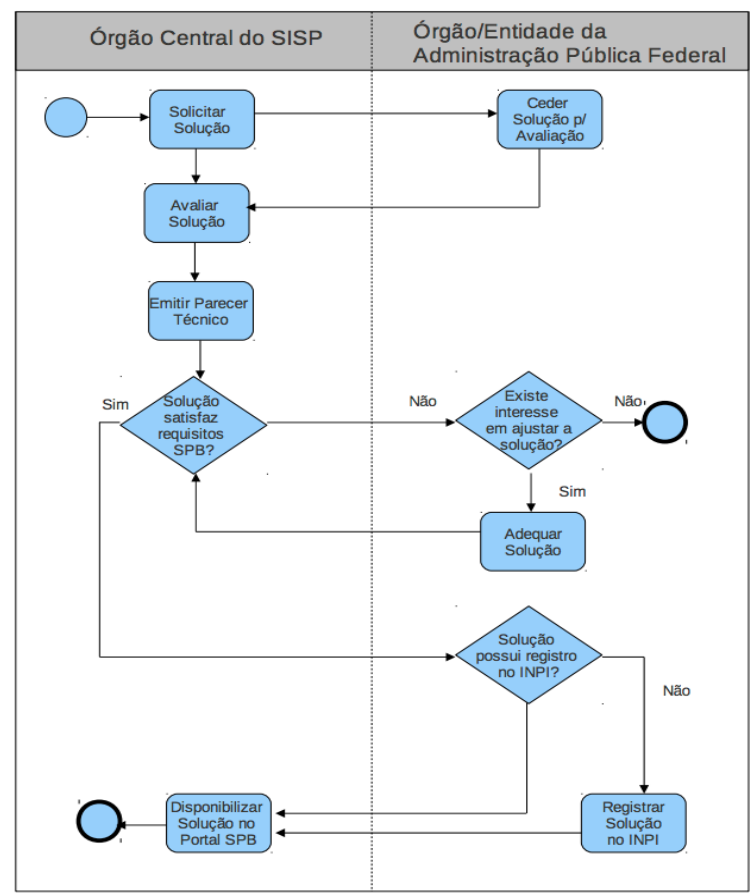

Figura 1.26. (A) Fluxograma do procedimento de oferta de software público brasileiro (B) Fluxograma do procedimento de solicitação de software público brasileiro

\section{Software Livre-Licença GNU/GPL}

Segundo o discutido em Neto e Nunes (2013), o Software Livre figura como uma corrente que se ampara em um idealismo pragmático, segundo Stallman (2002) e tem um teor filosófico ao abordar questões como valores e objetivos pautados em ajuda mútua e principalmente na liberdade (essa liberdade é evidenciada para os usuários em lugar dos ganhos monetários, conforme FSF (2013)).

Uma das justificativas defendidas pelos seguidores do Software Livre, onde um programa de computador não pode ser proprietário, é de que o mesmo é imaterial, se difere de objetos tangíveis, pode ser copiado e modificado mais facilmente por se tratar de uma informação digital, garantindo-lhe uma utilidade ímpar, conforme FSF (2013). Porém, deve-se salientar que o Software Livre também é passível de Registro, pois é considerado Programa de Computador convencional e, dessa forma, no Brasil, é protegido pela lei do Direito Autoral.

Para que um programa de computador possa ser considerado Software Livre, a Free Software Foundation - FSF coloca que os usuários desta modalidade precisam possuir quatro liberdades essenciais, conforme FSF (2013): (i) a liberdade de executar o programa, para qualquer propósito (liberdade 0); (ii) a liberdade de estudar como o programa funciona, e adaptá-lo às suas necessidades (liberdade 1). Para tanto, acesso ao 
código-fonte é um pré-requisito; (iii) a liberdade de redistribuir cópias de modo que você possa ajudar ao próximo (liberdade 2) e; (iv) a liberdade de distribuir cópias de suas versões modificadas a outros (liberdade 3 ).

No sentido garantir essa proposta de liberdade, a comunidade do Software Livre utiliza comumente a licença pública geral do GNU - GNU GPL, de acordo com Stallman (2002), utilizando um método chamado Copyleft, que exige que as derivações do programa também sejam Software Livre. O Copyleft é um termo genérico que vai de encontro ao conceito do Copyright propositalmente e garante a liberdade dos usuários, onde as derivações de um Software Livre também o serão. Ou seja, assumem as quatro liberdades que norteiam seu conceito.

\section{Como é criado o Software Livre?}

Para criar um Software Livre basta tornar seu código fonte disponível para toda a comunidade, deixando-o sobre domínio público. Deve-se acrescentar nos cabeçalhos dos arquivos dos códigos fonte as diretivas de licenciamento escolhida, a exemplo da GNU/GPL. Quanto ao registro do mesmo, como já falamos, ele pode ser feito sim, pois o fato de estar registrado, não impede seu(s) autor(es) e titular(es) de torná-lo livre, apesar de ser algo não tão bem aceito pela comunidade deste segmento. Por outro lado, o registro é uma garantia legal, neste caso, dos Direitos Morais estabelecidos através do Direito Autoral, e legalmente, em nosso território, o software é enquadrado neste cenário.

Assim, como descrito acima, nem o Registro de Programa de Computador, nem o Software Público Brasileiro, nem o GNU protege a funcionalidade ou a ideia de um software. Na próxima subseção são abordadas alternativas para proteção da funcionalidade.

\subsubsection{Propriedade Industrial em Software}

A Propriedade Industrial difere da Propriedade Intelectual devido a algumas características inerentes que o produto a ser patenteado deve apresentar a fim de garantir a patenteabilidade. Em Registro de Programa de Computador essas questões inexistem pois, não se protege a funcionalidade do "produto" e sim a "obra literária" resultante dele, ou seja, nesse caso, o "emaranhado de palavras ou códigos, disposto da forma em que se apresenta". Como visto anteriormente, a Lei de Propriedade Intelectual brasileira protege os Programas de Computador por meio da Lei do Direito Autoral. Contudo, a lei de Propriedade Industrial não concede patente para software isolado no Brasil (como acontece em outros países, como nos USA, o UPSTO concede patente, por exemplo. O UPSTO não assinou o TRIPS (2012)).

A lei de Propriedade Industrial brasileira concede patente ao equipamento com software embarcado considerando o produto em si e não somente o software que faz ele funcionar. $\mathrm{O}$ equipamento com software embarcado que caracterize inovação pode ser objeto de proteção patentária, obedecidas as prescrições da Lei $n^{0} 9.279 / 96$, conforme INPI (2013).

A patente dura 20 anos e é de abrangência nacional diferente do Direito Autoral que dura 50 anos com abrangência internacional. Caso exista o interesse de uma cartapatente internacional, deve-se encaminhar o pedido a um escritório internacional via PCT, o tempo de duração da patente internacional para software é de 20 anos, segundo Russo et al. (2012). Para que um produto (invenção) possa receber uma patente no país 
(ou internacionalmente), ele deve apresentar três requisitos básicos: novidade, atividade inventiva e aplicabilidade/aplicação industrial.

Segundo Russo et al. (2012):

\begin{abstract}
uma invenção é considerada nova quando não faz parte do Estado da Arte ou Estado da Técnica (arte ou técnica prévia)"; "uma invenção é considerada como possuindo atividade inventiva se ela não é óbvia para um técnico no assunto em relação ao estado da técnica"; Uma invenção é considerada como possuindo aplicação industrial se ela pode ser fabricada ou utilizada por qualquer tipo de indústria, Russo et al. (2012)
\end{abstract}

Caso o software não seja embarcado, ele ainda pode ser passível de patente de processo. Porém isso é possível se existir algum processo no software passível de produção industrial, com atividade inventiva e novidade, que na maioria das vezes é embarcado. O que será passível de patenteamento é somente o processo e o produto, não o software em sua completude.

Em 2012, O INPI abriu uma consulta pública sobre patentes que envolvem Programas de Computador, conforme INPI (2012). Várias entidades brasileiras, tais como, Software Livre Brasil, CCSL-USP (Centro de Competência em Software Livre da Universidade de São Paulo) e FGV se manifestaram contra essa consulta, de acordo com USP (2012). O CCSL-USP e o FGV realizaram um estudo que foi enviado ao INPI dotado de um parecer com argumentos concretos do ponto de vista jurídico sobre a questão das patentes de software e os problemas encontrados nos procedimentos divulgados pelo o INPI para os pedidos de patentes de software, conforme USP (2012). Devido à repercussão o INPI, tirou do ar a consulta púbica.

Tanto a Propriedade Intelectual (Direito Autoral) quanto a Propriedade Industrial (patente) é passível de transferência via contrato averbado no INPI. Caso exista o interesse de uma carta-patente internacional do software registrado no Brasil ou software embarcado com patente submetida, deve-se encaminhar o processo via PCT aos escritórios internacionais.

\title{
Como é feito o depósito da patente?
}

É importante salientar que a Patente quando envolve o Software Embarcado não é literalmente uma Patente de Software, o que na prática não protege seguramente a propriedade intelectual sobre o software de maneira isolada. O processo de depósito de Patente envolvendo Software Embarcado segue o mesmo trâmite de qualquer processo de patente junto ao INPI. Para mais detalhes, o órgão disponibiliza o Guia de Tramitação de Patentes em seu site, conforme INPI (2013).

\subsubsection{Outras tipos de Propriedade Intelectual em Informática na Educação}

Outros ativos intelectuais relacionados à Informática na Educação também podem ser protegidos. Pesquisadores na área educacional muitas vezes se apropriam de ativos sem conhecimento da legislação que os rege. Essa seção apresenta os diversos tipos de PI que podem estar envolvidas em uma página na Internet, por exemplo, passíveis de Propriedade Intelectual.

Conforme o PPGPI (2013), os conteúdos publicados e/ou veiculados na Internet não são completamente públicos, ou seja, não pertencem à coletividade, nem podem ser usados de forma livre e gratuita como muitos pesquisadores em Educação o fazem. 
Apresenta-se alguns artigos da Lei do Direito do Autor - LDA (2012) que regem esse discurso: (i) Art.7 da Lei de Direitos Autorais estabelece a proteção das obras "expressas por qualquer meio ou fixada sem qualquer suporte, tangível ou intangível, conhecido ou que se invente no futuro"; (ii) Art. 33 da Lei de Direitos Autorais determina que "ninguém pode reproduzir obra que não pertença ao domínio público, a pretexto de anotá-la, comentá-la ou melhorá-la, sem permissão do autor; (iii) Art. 68. Sem prévia e expressa autorização do autor ou titular, não poderão ser utilizadas obras teatrais, composições musicais ou lítero-musicais e fonogramas, em representações e execuções públicas; (iv) Art. 29. Depende de autorização prévia e expressa do autor a utilização da obra, por quaisquer modalidades, tais como: I - a reprodução parcial ou integral; II - a edição; III - a adaptação, o arranjo musical e quaisquer outras transformações; IV - a tradução para qualquer idioma; V - a inclusão em fonograma ou produção audiovisual...

Na Figura 1.27 apresenta-se um conjunto de cenários reais dessa proteção, segundo a Lei do Direito do Autor:

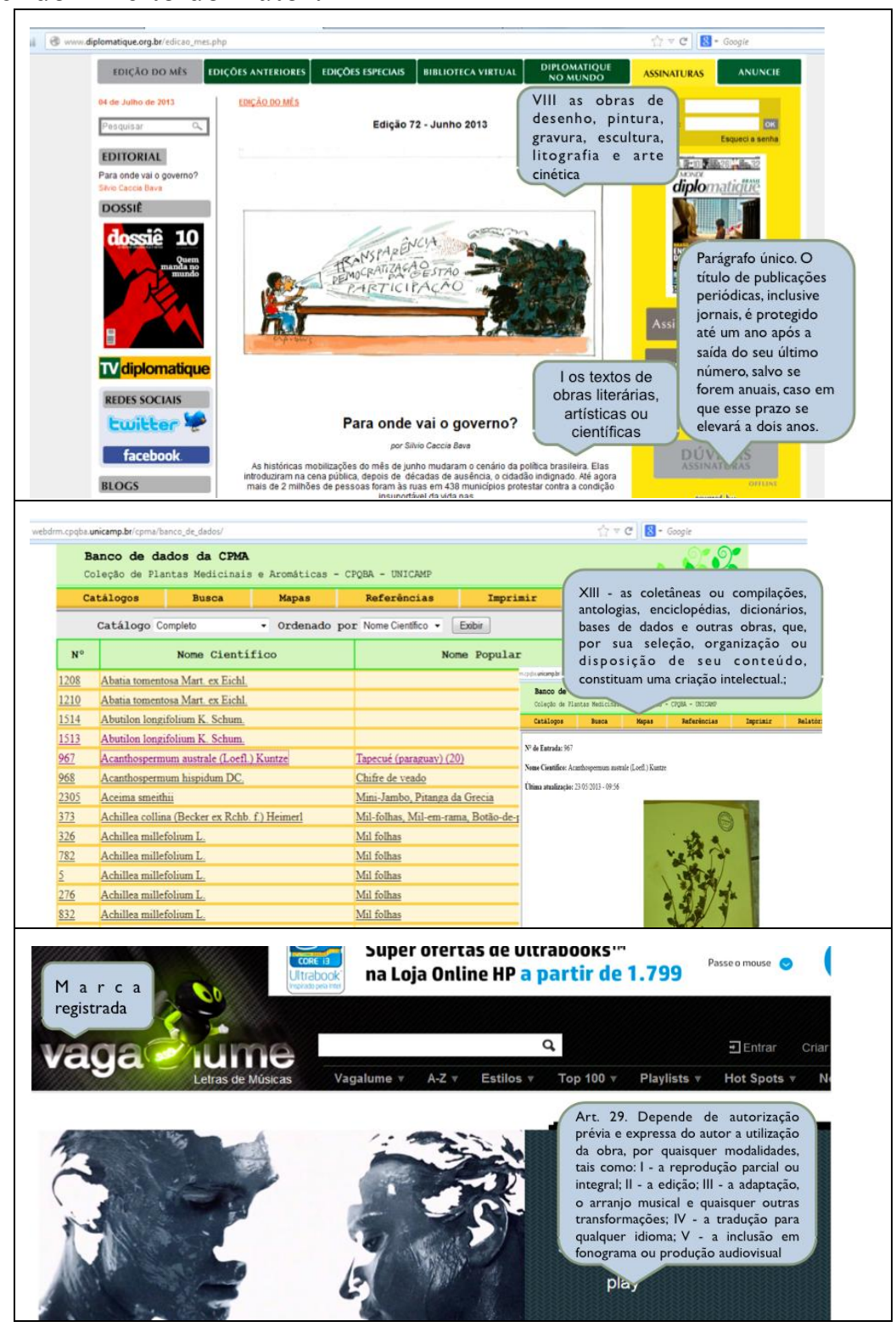




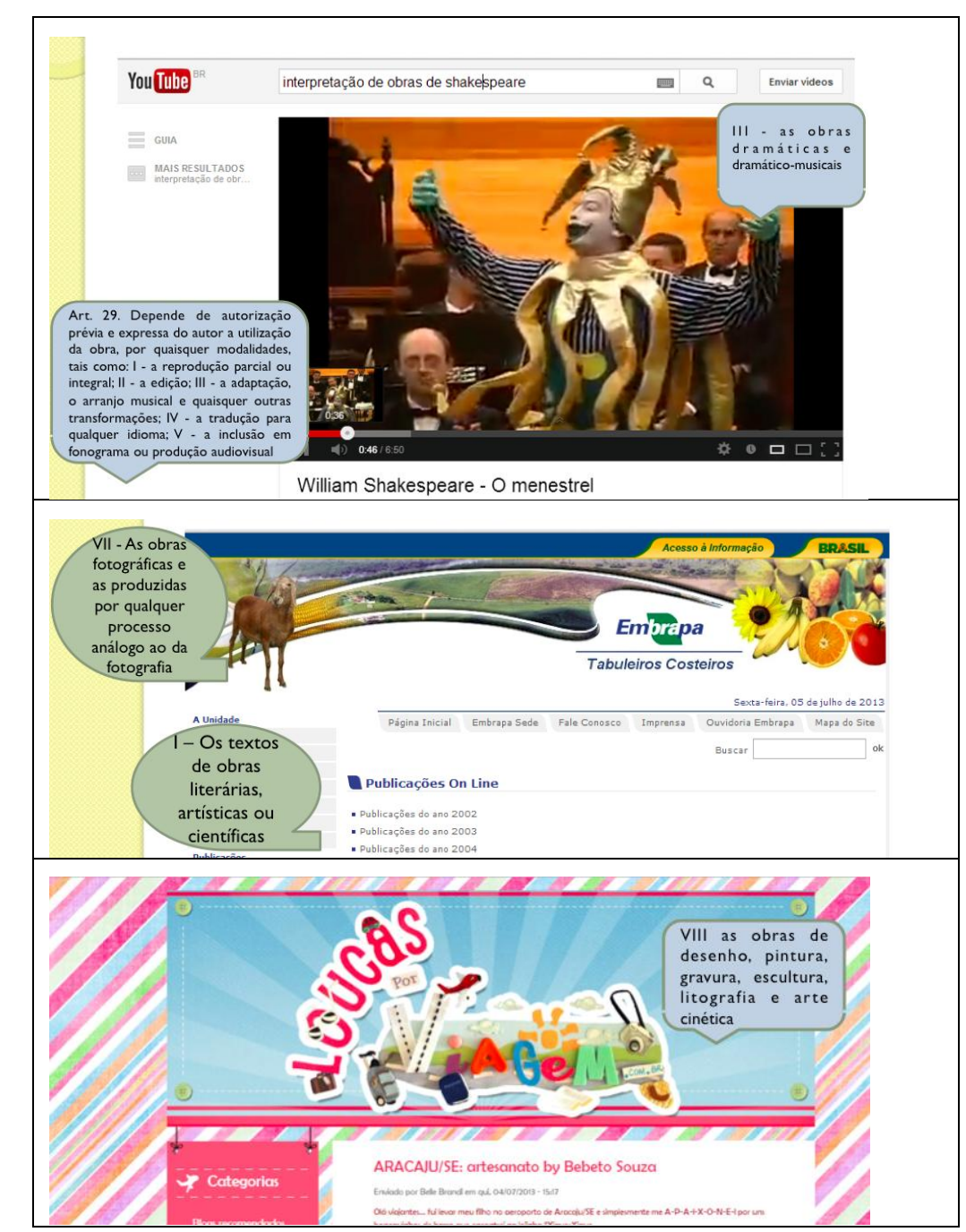

Figura 1.27. Cenários de Propriedade Intelectual na Internet

\subsection{Conclusão}

Este capítulo destinou-se aos acadêmicos (graduação e de pós-graduação), profissionais, professores e empresários interessados em compreender sobre prospecção com base nas produções científicas e tecnológicas produzidas em seu ambiente de trabalho, principalmente na área de Informática na Educação. O capítulo ainda detalhou as mais reputadas bases de busca para a construção de uma prospecção de qualidade. Dissertou, também, sobre conceitos de propriedade intelectual e industrial, envolvendo principalmente programas de computador e ativos apropriáveis disponíveis via Internet e muitas vezes usadas de forma inapropriada pelos profissionais da área Educacional. Como trabalho futuro é interessante, também tratar os aspectos de propriedade intelectual envolvendo outros ativos educacionais importantes, tais como, objetos de aprendizagem, recursos educacionais abertos, tecnologias educacionais, e recursos de acessibilidade, entre outros.

\section{Referências}

CIP (Classificação Internacional de Patentes). Oitava Edição. INPI 2006. (Disponível em http://ipc.inpi.gov.br/IPCpubPrep/Full-BR/guide/br/guide.pdf (classificação online http://ipc.inpi.gov.br/ipcpub/\#refresh=page)). Acessado: 12/09/2013. 
Cruz. C.H.B.. "A Universidade, a Empresa e a Pesquisa que o país precisa". In: Parcerias Estratégicas. MCT, Centro de Estudos Estratégicos (CEE), Brasilia: DF. ISSN 1413-9375, $\mathrm{n}^{\circ} .8,2000$.

De Negri, F.; Cavalcante, L.R.. "Sistemas de inovação e infraestrutura de pesquisa: considerações sobre o caso brasileiro". In: 24a Radar - tecnologia, produção e comércio exterior. IPEA- Diretoria de Estudos e Políticas Setoriais, de Inovação, Regulação e Infra estrutura. Brasília, 2013.

Derwent. Derwent Innovations Index. 2013 (Disponível em : http://thomsonreuters.com/derwent-innovations-index/ ). Acessado: 20/09/2013.

EPO. European Patent Office. 2013. (Disponível em : http://www.epo.org/) Acessado: 20/09/2013.

EPO. "A comprehensive overview of the coverage of the worldwide patent database managed by the EPO". In: Global Patent Data Coverage 2011. (Disponível em : $<$ http://documents.epo.org/projects/babylon/eponet.nsf/0/204052542F7D7507C12572EB004 55D35/\$File/comprehensive_overview.pdf) Acessado: 20/09/2013.

FSF. Free Software Fundation. Licença Creative Commons GNU GPL 2.0. 2013. (Disponível em http://creativecommons.org/licenses/GPL/2.0/legalcode.pt) Acessado: 12/03/2013.

INPI-Consulta pública sobre "Patente em invenções implementadas por computador". 2012 (Disponível em http://convergenciadigital.uol.com.br/cgi/cgilua.exe/sys/start.htm?infoid=29693\&sid=3). Acessado: 12/09/2012.

INPI. Instituto Nacional de Propriedade Industrial. 2013 (Disponível em: http://www.inpi.gov.br/). Acessado: 12/03/2013.

LDA. Lei do Direito do Autor -LEI No 9.610, DE 19 DE FEVEREIRO DE 1998. 1998.(Disponível em http://www.planalto.gov.br/ccivil_03/leis/19610.htm ). Acessado: 12/09/2012.

LS. Lei de Software - LEI No 9.609, DE 19 DE FEVEREIRO DE 1998. 1998. (Disponível em http://www.planalto.gov.br/ccivil_03/leis/L9609.htm). Acessado: 12/09/2012.

LI. Lei da Inovação, n. ${ }^{\circ} 10.973$, de 2 de dezembro de 2004. Dispõe sobre incentivos à inovação e à pesquisa científica e tecnológica no ambiente produtivo e dá outras providências. Diário Oficial [da] República Federativa do Brasil, Brasília, DF, 3 dez. 2004. Disponível em: < http://www.planalto.gov.br/ccivil_03/_ato2004-2006/2004/lei/110.973.htm>. Acessado em: 13/05/2013.

Neto, P. E e Nunes, M. A. S. N. "Proteção de Ativos Intelectuais de TI : Mecanismos de proteção no território brasileiro". SEMINFO. Accepted paper.

Nunes, M. A. S. N. ; Cazella, S. C. ; Pires, E. A. ; Russo, S. L. . "Discussões Sobre Produção Acadêmico-Científica \& Produção Tecnológica: Mudando Paradigmas" . In: Revista GEINTEC- Gestão , Inovação e Tecnologias, v. 3, p. 205-220, 2013.

PCT. Patent Cooperation Treaty. 2013. Disponível em http://www.wipo.int/pct/en/pct_contracting_states.html. Acessado em 30/09/2013.

PPGPI. Relatório da Disciplina Propriedade Intelectual- "Sites web e conexos". PPGPI-UFS. 2013.

RS. Registro de Software. INSTRUÇÃO NORMATIVA No 11/2013. In Normas do INPI 2013. (Disponível 
http://www.inpi.gov.br/images/stories/downloads/pdf/Normas_Auditoria_Final_15_3_2013_ C.pdf). Acessado: 12/03/2013.

Russo, S. L. ; Silva, G. F. ; Oliveira, L. B. ; Santos, M. M. A. ; Nunes, M. A. S. N. ; Vasconcelos, J. S. .” Propriedade Intelectual.” In: Russo, S.L.;Silva, G.F.; Nunes, M.A.S.N... Capacitação em inovação tecnológica para empresários - Edição 2. 2ed.s: Editora UFS, 2012b, v. , p. 55-91.

Russo, S. L; Silva, G. F.; Nunes, M. A. S. N.. Capacitação em inovação tecnológica para empresários - Edição 2. 2. ed. São Cristóvão: Editora UFS, 2012. v. 1. 288p .(Disponível em http://200.17.141.213/ gutanunes/hp/publications/capacite.pdf). Acessado: 12/09/2012.

SPB. Software Público Brasileiro . Instruções Normativas No 01, DE 17 DE JANEIRO DE 2011. 2011. (Disponível em http://www.softwarepublico.gov.br/spb/download/file/in_spb_01.pdf). Acessado: $12 / 09 / 2012$.

Scholze, S.: Chamas, C.. "Instituições Públicas de Pesquisa e o Setor Empresarial: o papel da inovação e da propriedade intelectual". In: Parcerias Estratégicas. MCT, Centro de Estudos Estratégicos (CEE), Brasilia: DF. ISSN 1413-9375, nº. 8, mao, 2000.

SEI - Science And Engineering Indicators. National Science Board Editor, 2012.

Stallman, Richard. "Copyleft: Um Idealismo Pragmático". In: Free Software, Free Society: The Selected Essays of Richard M. Stallman. 2002. (Disponivel em http://www.gnu.org/philosophy/pragmatic.html). Acessado: 12/03/2013.

TRIPS. Trade-Related Aspects of Intellectual Property Rights. 2012 (Disponível em http://www.inpi.gov.br/images/stories/27-trips-portugues1.pdf). Acessado: 12/09/2012.

UNESCO. Science Report 2010: The Current Status of Science around the World. UNESCO Publishing. $2010 . \quad$ Disponível em: $<$ http://unesdoc.unesco.org/images/0018/001899/189958e.pdf>. Acessado: 12/03/2013.

USP - Carta aberta ao INPI sobre Patente. 2012. (Disponível em http://ccsl.ime.usp.br/pt$\mathrm{br} /$ news/12/03/20/ccsl-usp-divulga-carta-aberta-ao-inpi-sobre-patentes-de-software). Acessado: 12/03/2012.

USPTO. United States Patent and Trademark Office. 2013. (Disponível em : http://www.uspto.gov/ ). Acessado: 20/09/2013.

WIPO. World Intellectual Property Organization. 2013 (Disponível em http://www.wipo.int/). Acessado: 20/09/2013.

WIPO-PATENTSCOPE. 2013 (Disponível em http://patentscope.wipo.int/). Acessado: 20/09/2013. 